Document downloaded from:

http://hdl.handle.net/10251/121748

This paper must be cited as:

Carozzi, FG.; Poggi, C.; Bertolesi, E.; Milani, G. (2018). Ancient masonry arches and vaults strengthened with TRM, SRG and FRP composites: Experimental evaluation. Composite Structures. 187:466-480. https://doi.org/10.1016/j.compstruct.2017.12.075

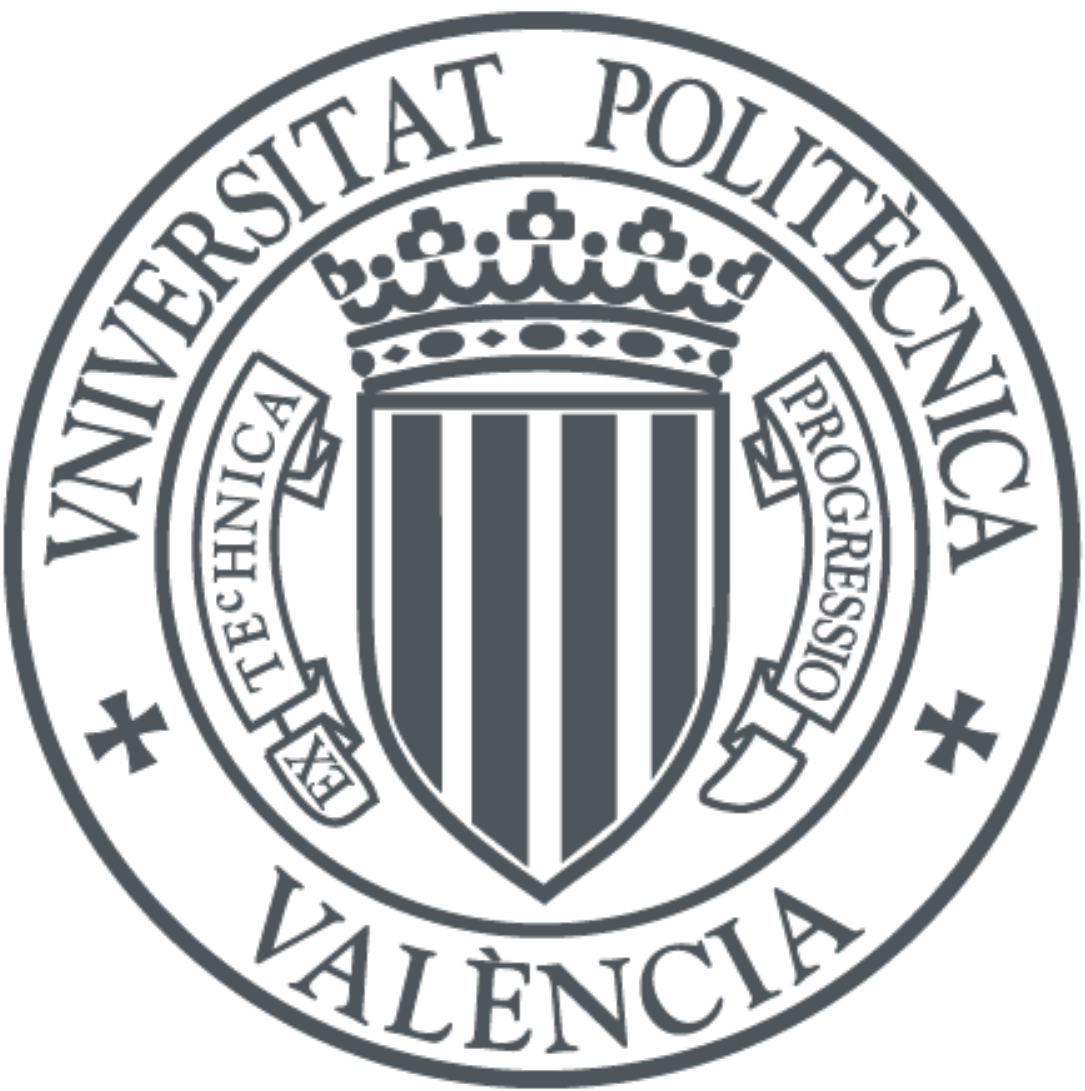

The final publication is available at

http://doi.org/10.1016/j.compstruct.2017.12.075

Copyright Elsevier

Additional Information 


\section{Accepted Manuscript}

Ancient masonry arches and vaults strengthened with TRM, SRG and FRP composites: Experimental evaluation

Francesca Giulia Carozzi, Carlo Poggi, Elisa Bertolesi, Gabriele Milani

PII: S0263-8223(17)33585-7

DOI: https://doi.org/10.1016/j.compstruct.2017.12.075

Reference: COST 9232

To appear in:

\section{Composite Structures}

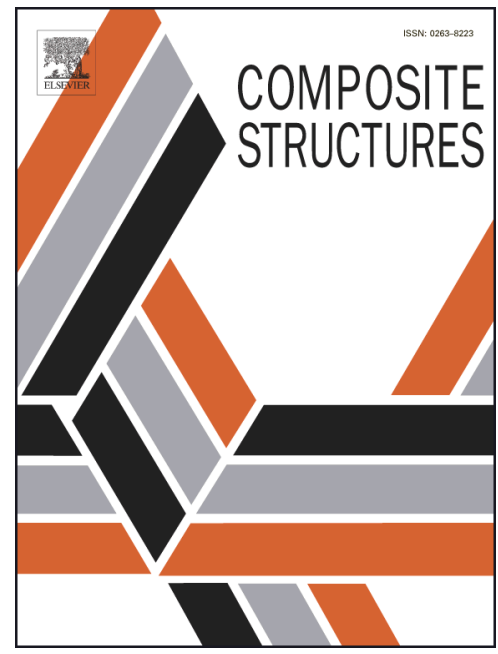

Received Date: $\quad 30$ October 2017

Revised Date: $\quad 14$ December 2017

Accepted Date: $\quad 28$ December 2017

Please cite this article as: Carozzi, F.G., Poggi, C., Bertolesi, E., Milani, G., Ancient masonry arches and vaults strengthened with TRM, SRG and FRP composites: Experimental evaluation, Composite Structures (2017), doi: https://doi.org/10.1016/j.compstruct.2017.12.075

This is a PDF file of an unedited manuscript that has been accepted for publication. As a service to our customers we are providing this early version of the manuscript. The manuscript will undergo copyediting, typesetting, and review of the resulting proof before it is published in its final form. Please note that during the production process errors may be discovered which could affect the content, and all legal disclaimers that apply to the journal pertain. 


\title{
Ancient masonry arches and vaults strengthened with TRM, SRG and FRP composites: Experimental evaluation
}

\author{
Francesca Giulia Carozzi, Carlo Poggi, Elisa Bertolesi, Gabriele Milani ${ }^{1}$ \\ Department of Architecture, Built environment and Construction engineering ABC \\ Politecnico di Milano \\ Piazza Leonardo da Vinci 32, 20133, Milan (Italy)
}

\begin{abstract}
Composite materials made with textile fibers both with polymeric and cementitious matrices are often adopted for the retrofitting of masonry arches and vaults. A specific project that analyzes the performance of ancient masonry arches and vaults strengthened with composite systems has been recently concluded at Politecnico of Milan. The project involves the experimental evaluation and the development of numerical and analytical simulations. In this paper the experimental campaign is described, whereas the numerical validation is provided in an accompanying paper [1]. The tests were performed in-situ on ancient masonry arches and vault elements. In particular, three barrel vaults and two arches either unreinforced or reinforced with Steel Reinforced Grout (SRG), Textile Reinforced Mortar (TRM) and Fiber Reinforced Polymer (FRP) were tested.

The arches had a span equal to $3.30 \mathrm{~m}$, a rise equal to $0.83 \mathrm{~m}$ and were built with common Italian bricks regularly spacing out two bricks laid edge on (thickness of the arch $12 \mathrm{~cm}$ ) with two bricks (one over the other) disposed in single leaf. Barrel vaults had the same geometry of the arches but were made with a single leaf. In all cases, an eccentric vertical load was applied at $1 / 4$ of the span and was increased up to failure. The experimental results on unreinforced structures are compared with those obtained on the strengthening ones in terms of failure mode, maximum load, stiffness and ductility.
\end{abstract}

Keywords: masonry; arches and vaults; Textile Reinforced Mortar TRM; FRP; in situ experimentation

\section{Introduction}

\subsection{Problem statement}

Masonry arches and barrel vaults are quite widespread all over Europe, especially in Italy. They have been used for centuries in different kinds of constructions, such as monuments but also in common residential buildings and bridges, the main advantage is the capability to cover larger spans and carry relatively heavy gravity loads. The structural stability is guaranteed when thrust lines remain all inside the thickness. This is a consequence of the fairly good masonry compression strength and the almost vanishing tensile resistance. In the past, starting from Roman age ongoing the arch design was essentially based on empirical rules, but what was intuitively correct for vertical loads, i.e. to enforce masonry working in compression, is unfortunately not very straightforward in presence of horizontal inertia forces induced by an earthquake. As a matter of fact, in presence of a seismic excitation, the line of thrust shifts easily outside the arch thickness, resulting into a damage spreading and the progressive collapse characterized by the formation of a typical four hinges mechanism. Such

\footnotetext{
${ }^{1}$ Corresponding author. E-mail: gabriele.milani@polimi.it
} 
inadequate resistance of arches and vaults under seismic actions is an issue that all engineers at both professional and academic level have been facing for about 20 years, at least starting from the collapse of one vault of the S. Francesco Basilica in Assisi during Umbria earthquake (26 September 1997). The need of designing efficient and non-invasive strengthening interventions to masonry vaults in seismic area appeared almost immediately clear to all technicians involved in the post seismic reconstruction, but unfortunately conventional retrofitting techniques, such as external reinforcement with steel plates, surface concrete coating and welded mesh, have proven to be impractical and time expensive, adding also considerable seismic mass. The utilization of Fiber Reinforced Polymer (FRP) before and Textile Reinforced Mortar (TRM) only recently appears particularly effective, because both strengthening technologies may give a significant contribution in the zones where they are applied in precluding the opening of flexural hinges.

FRP polymers are well known materials made with textile reinforcements and epoxy resins. TRM materials are composed of two layers of inorganic matrix (lime or cementitious mortar) with interposed one layer of fiber textile (glass, carbon, PBO, steel or basalt fibers). This system presents many advantages compared to FRPs as higher moisture permeability, compatibility with the masonry substrate and reversibility [2]. Both these systems present a larger stiffness incompatible with the historical masonry substrate, which is much more deformable, but the failure mode of TRM characterized by a progressive mortar cracking and slippage phenomena of the textile increased the ductility of the retrofitting structure.

\subsection{Previous studies}

In the last decade many experimental and numerical studies were performed on masonry arches reinforced with FRP materials. Several studies [3]-[6], demonstrated the efficiency of this reinforcement technique, both in terms of the maximum load applied and of displacement at collapse. In some cases the application of a continuous FRP textile prevented the formation of the typical hinge-based failure mode and the collapse was caused by debonding of the FRP.

If the reinforcement was applied at the intrados of the arches the collapse was due to the debonding of the FRP from the substrate and this reason in some cases also the use of FRP anchor spikes was investigated [5], [7]. In [8] it was shown that the FRP application at the extrados is the most effective option to increase the strength of the structure; on the contrary when the reinforcement is applied at the intrados, the ductility of the arch seems slightly increased

In the last years the study of reinforcement of masonry structures was extended to TRM materials, that present many advantages compared to FRP [9]-[11]. Due to their wide spread in European and Italian constructions and to the specific mechanical behaviour, an important item is the study of retrofitting of masonry arches and vaults [12].

In [13] Borri and co-workers performed a series of tests on masonry arches reinforced with Steel Reinforced Polymer (SRP) and Steel Reinforced Grout (SRG) materials applied at the extrados or at the intrados. The experimental results showed that the arches strengthened at the intrados provided a higher ultimate strength with respect to the one of the extrados reinforced structures. The SRG system seemed to be more effective than the SRP and provided better bond properties with the masonry substrate, in particular the maximum strain reached in the test on SRG reinforced arch was about twice the one reached in SRP reinforced structure.

In [14] masonry arches strengthened at the intrados or extrados with PBO-FRCM systems were studied. The experimental results were compared with the performance of a FRP reinforcement. The PBO-FRCM system demonstrated to be effective in increasing the collapse load, with an increment of about $400 \%$ with respect to the un-strengthened element. Also the ductility presented a significant increment when the reinforcement was applied at the extrados. The comparison between the structures reinforced with FRCM and FRP systems showed a higher performance of the FRP system in terms of maximum load. Instead, in terms of ductility, the FRP reinforced arch presented a brittle failure with a lower ductility value. 
In [15] an experimental investigation on full-scale vaults built in a laboratory and retrofitted at the extrados with a TRM material was presented. The results showed a significant increment of the loadcarrying capacity and of the displacement. The reinforcement prevented the activation of the typical four hinges mechanism and the development of cracks at the extrados.

In [16] the authors presented the results of a series of destructive in-situ tests performed on existing masonry arches strengthened with FRCM systems with different configurations. The results showed an increment in the load-carrying capacity and in the deflection of the reinforced structures. The reinforcement systems did not prevent the formation of four hinges.

The previous papers presented an experimental set-up with the arch structure fixed at the abutments and subjected to a concentrated vertical load applied at about a quarter of the span. In [17] a different test set-up was proposed where the load was horizontally applied by two manual pump that distributed the load in eight sections in order to simulate a horizontal action proportional to the vault mass. The tests were performed on vaults retrofitted with FRCM materials applied in different configurations to analyze the response of these elements subjected to seismic excitation and understand the actual behavior of the reinforcement.

\subsection{Objective of the research}

The retrofitting of ancient masonry arches and vaults was investigated in this project. The paper presents the results of a detailed in-situ investigation on three barrel vaults and two arches either unreinforced or reinforced with Steel Reinforced Grout (SRG), Textile Reinforced Mortar (TRM) and Fiber Reinforced Polymer (FRP). The arches were originally built with common Italian bricks regularly spacing out two bricks laid edge on with two bricks (one over the other) disposed in single leaf. One of the two arches is tested unreinforced, whereas the second is reinforced with an SRG constituted by an inox grid embedded into a layer of lime mortar. Barrel vaults, having the same geometry of the arches, are single leaf structures and they are tested either unreinforced or with alternatively an extrados FRP and TRM reinforcement. In all cases, an eccentric vertical load placed at $1 / 4$ of the span is increased up to failure. The experimental results on unreinforced structures are compared with those obtained on the strengthening ones in terms of maximum load, stiffness and ductility. The reinforcement systems were very effective and modified the typical collapse model.

\section{Experimental investigation}

\subsection{Geometry of the tested elements}

The in situ experimentation was performed on a ribbed barrel vault belonging to an ancient masonry building located in the countryside close to Novi Ligure (north-west of Italy) and originally built at the beginning of the last century. A peculiar characteristic of such structure, also typical of many other coeval buildings in the same region, is that the basement and the ground floor walls (where the vault was located) are made with adobe and gravels. A section of the building is sketched in Figure 1a.

Prior experimentation, the ribbed barrel vault (Figure 1b) was transversally cut in order to isolate the arch ribs to obtain from the unribbed part three tile barrels (Figure 1c).

The arches are $250 \mathrm{~mm}$ wide, with a span equal to $3.30 \mathrm{~m}$ and a rise equal to $0.83 \mathrm{~m}$. The tile vaults have the same dimensions, exception made for the width that in this latter case is equal to $300 \mathrm{~mm}$. Arch and vault thicknesses are respectively 120 and $60 \mathrm{~mm}$. The arches were built with common Italian bricks with dimensions $250 \times 120 \times 55 \mathrm{~mm}$ and $10 \mathrm{~mm}$ thick mortar joints, regularly spacing out two bricks laid edge on with two bricks (one over the other) disposed in single leaf. The geometry is reported in Figure 2. 


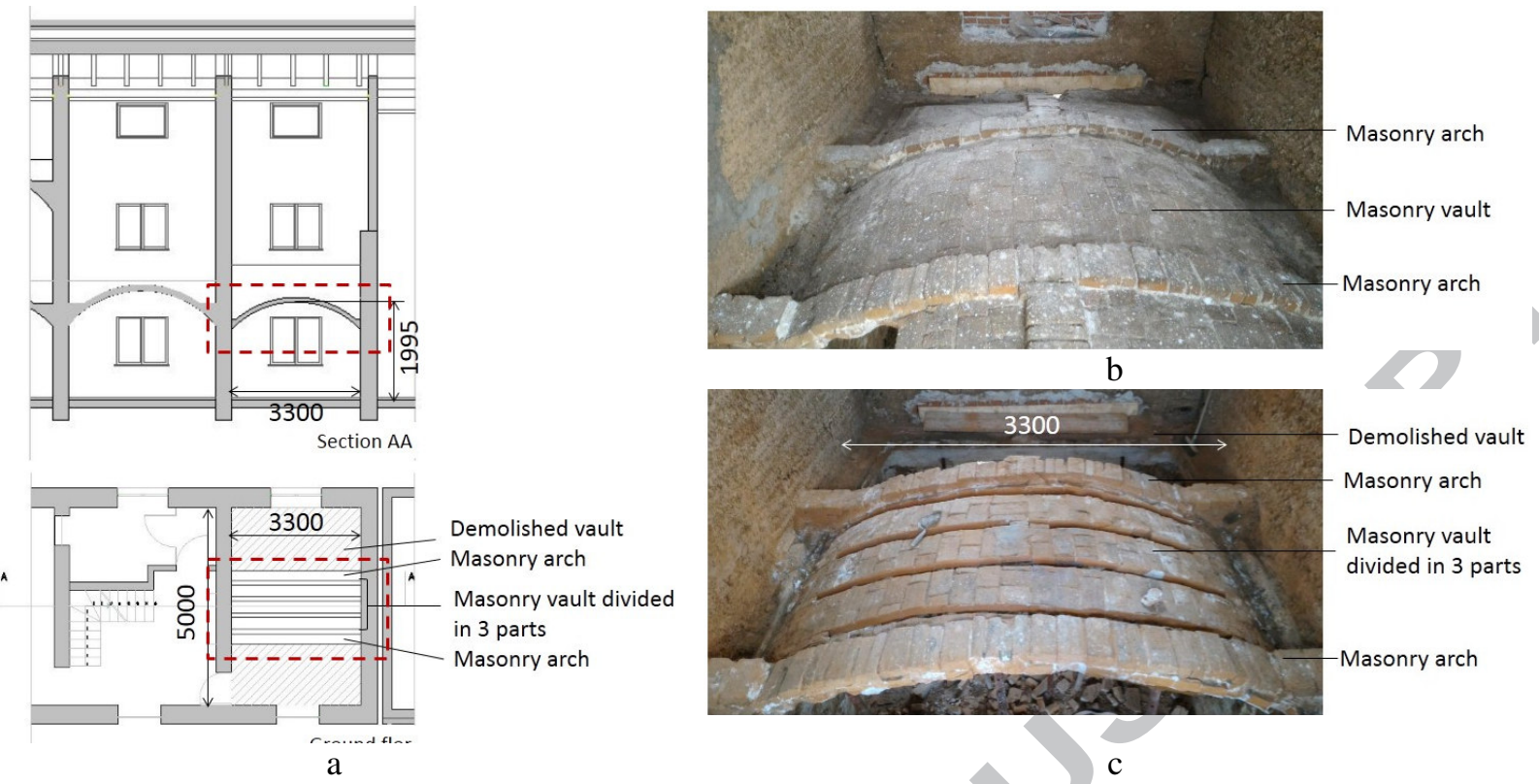

Figure 1: Geometry of the building [in mm]. -a: section. - b: existing ribbed vault. $-\mathrm{c}$ : the structural elements (vaults and arches) after the cutting

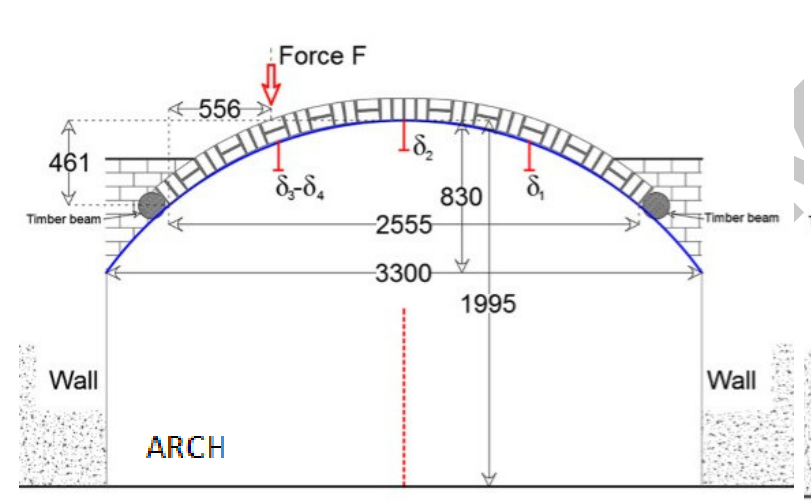

a)

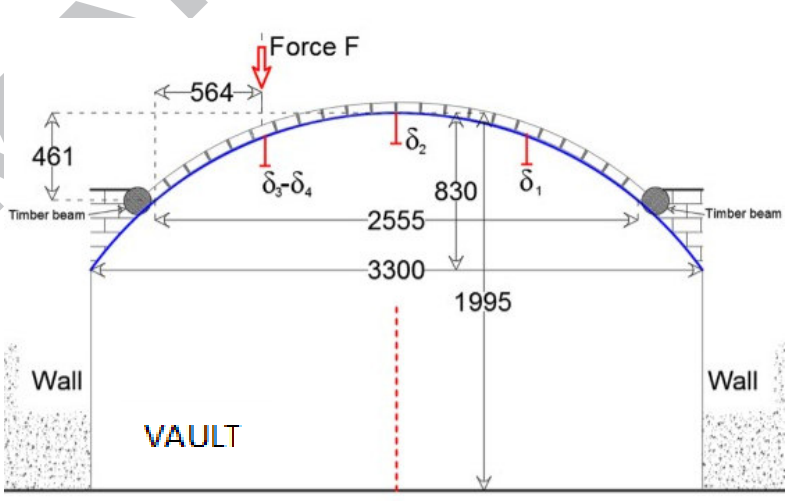

b)

Figure 2: Geometrical properties [mm]: -a: masonry arch. -b: masonry vault

The structural experimental investigation was carried out on two masonry arches and on three vaults, as summarized in Table 1 and depicted in Figure 1-c. The first arch, hereafter called U_A, is un-strengthened, whereas the second one (SRG_A) was reinforced with a Steel Reinforced Grout SRG at the extrados. The first vault is again un-strengthened, whereas the remaining two were reinforced with a CFRP system (FRP_V) and with a Textile Reinforced Mortar (TRM_V) coat at the extrados composed by a lime mortar and a glass fiber grid. This layout was chosen in order to analyze and compare the efficiency of three reinforcement systems constituted by two very different matrices (epoxy resin and lime mortar) and three textile materials (carbon, glass and steel). Due to the higher mechanical properties of the steel textile, the SRG was applied on the arch, that obviously presented a greater mechanical behavior.

The Steel Reinforced Grout (SRG) was constituted by two layers of inorganic lime mortar $(5+5$ $\mathrm{mm}$ ) and one layer of steel textile. The uniaxial textile was made by cords, about $6 \mathrm{~mm}$ stepped, each of which obtained by twisting 19 wires, the total cross section area being equal to $0.607 \mathrm{~mm}^{2}$, 
see Figure 3-a. Being the width of the arch equal to $250 \mathrm{~mm}$ the cross section of the steel textile was $25.5 \mathrm{~mm}^{2}$.

The textile reinforced mortar (TRM) system consisting of two main elements, namely an inorganic lime mortar and a glass fiber grid. The textile was a balanced grid with fiber yarns disposed in two orthogonal directions at a nominal distance of $20 \mathrm{~mm}$. The equivalent fiber thickness was $0.048 \mathrm{~mm}$ in both directions, see Figure 3-b. The width of the vaults was equal to $250 \mathrm{~mm}$ and 15 yarns were regularly positioned in the longitudinal direction of the vault. The total transversal area of the glass fibers was $12.0 \mathrm{~mm}^{2}$.

The FRP system consisting of a unidirectional carbon fibers textile was applied using an epoxy resin. The carbon textile had an equivalent thickness of $0.165 \mathrm{~mm}$ and a weight per unit area equal to $319.2 \mathrm{~g} / \mathrm{m}^{2}$, see Figure 3-c. The reinforcement width was equal to $100 \mathrm{~mm}$, so the total transversal section of the carbon fibers was equal to $16.5 \mathrm{~mm}^{2}$.

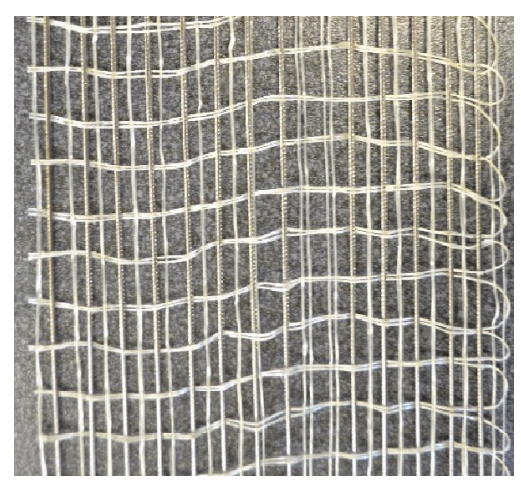

$-\mathrm{a}$

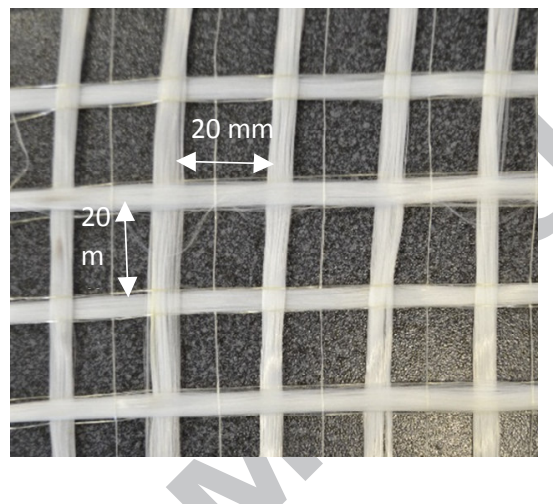

$-\mathrm{b}$

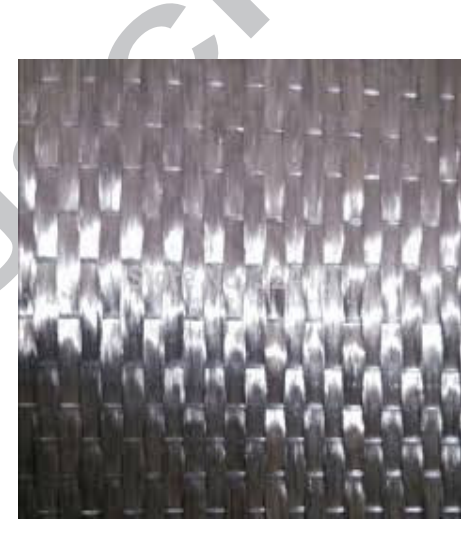

$-\mathrm{c}$

Figure 3: Textile geometries. $-\mathrm{a}$ : steel textile. $-\mathrm{b}$ : glass fibers grid. $-\mathrm{c}$ : carbon textile.

Table 1: experimentation carried out at a structural level and corresponding labels utilized.

\begin{tabular}{|c|c|c|c|c|}
\hline Structure & Reinforcement system & Name & $\begin{array}{c}\text { Structure } \\
\text { geometry [mm] }\end{array}$ & $\begin{array}{c}\text { Reinforcement } \\
\text { area }\left[\mathrm{mm}^{2}\right]\end{array}$ \\
\hline \multirow{2}{*}{ Arch } & Unreinforced & U_A & $3300 \times 250 \times 120$ & - \\
\hline & Steel Reinforced Grout & SRG_A & $3300 \times 250 \times 120$ & 25.5 \\
\hline & Unreinforced & U_V & $3300 \times 300 \times 60$ & - \\
\hline & $\begin{array}{c}\text { Glass Textile } \\
\text { Reinforced Mortar }\end{array}$ & TRM_V & $3300 \times 300 \times 60$ & 12.0 \\
\hline & $\begin{array}{c}\text { Carbon Fiber } \\
\text { Reinforced Polymer }\end{array}$ & FRP_V & $3300 \times 300 \times 60$ & 16.5 \\
\hline
\end{tabular}

2.2 Mechanical characterization of the components

A mechanical characterization of the masonry and of the reinforcing systems was performed. The single components were separately characterized and the tensile and bond properties of the systems were investigated. The knowledge of these properties is essential to evaluate the mechanical behaviour of the reinforcement system and to evaluate the main design parameters. The tensile tests are important to understand the strength and the elastic modulus in the elastic phase, the cracking behaviour, the adhesion between textile and matrix and the development of slippage phenomena. The bond tests are essential to study the adhesion between reinforcement system and substrate, between textile and inorganic matrix and evaluate the typical failure mode, that may be very different in each system. 


\subsubsection{Masonry properties}

The mechanical properties of the clay bricks were investigated according to [18]-[20]. Eight compressive tests produced an average compressive strength equal to $10.7 \mathrm{MPa}$ and an average elastic modulus equal to $2016 \mathrm{MPa}$. The tensile strength was evaluated equal to $0.8 \mathrm{MPa}$ with a Brazilian test. The original mortar was lime based, it was not possible to directly identify its mechanical properties.

A masonry specimen cut from the unreinforced arch was tested in compression to determine the mechanical properties of the masonry. In Figure 4a a sketch of the masonry element analyzed is represented; the dimensions and the tests set-up are reported in Figure 4 b. The compressive load was applied in the longitudinal direction of the arch. Two mortar layers were applied on the upper and lower sides of the sample to distribute homogeneously the load and regularize the geometrical imperfections. Four vertical LVDTs were applied on the mortar joint to estimate the elastic modulus of the mortar (Figure 5a). The test was performed under displacement control; the load was monotonically applied at a rate of $5 \mathrm{~mm} / \mathrm{min}$.

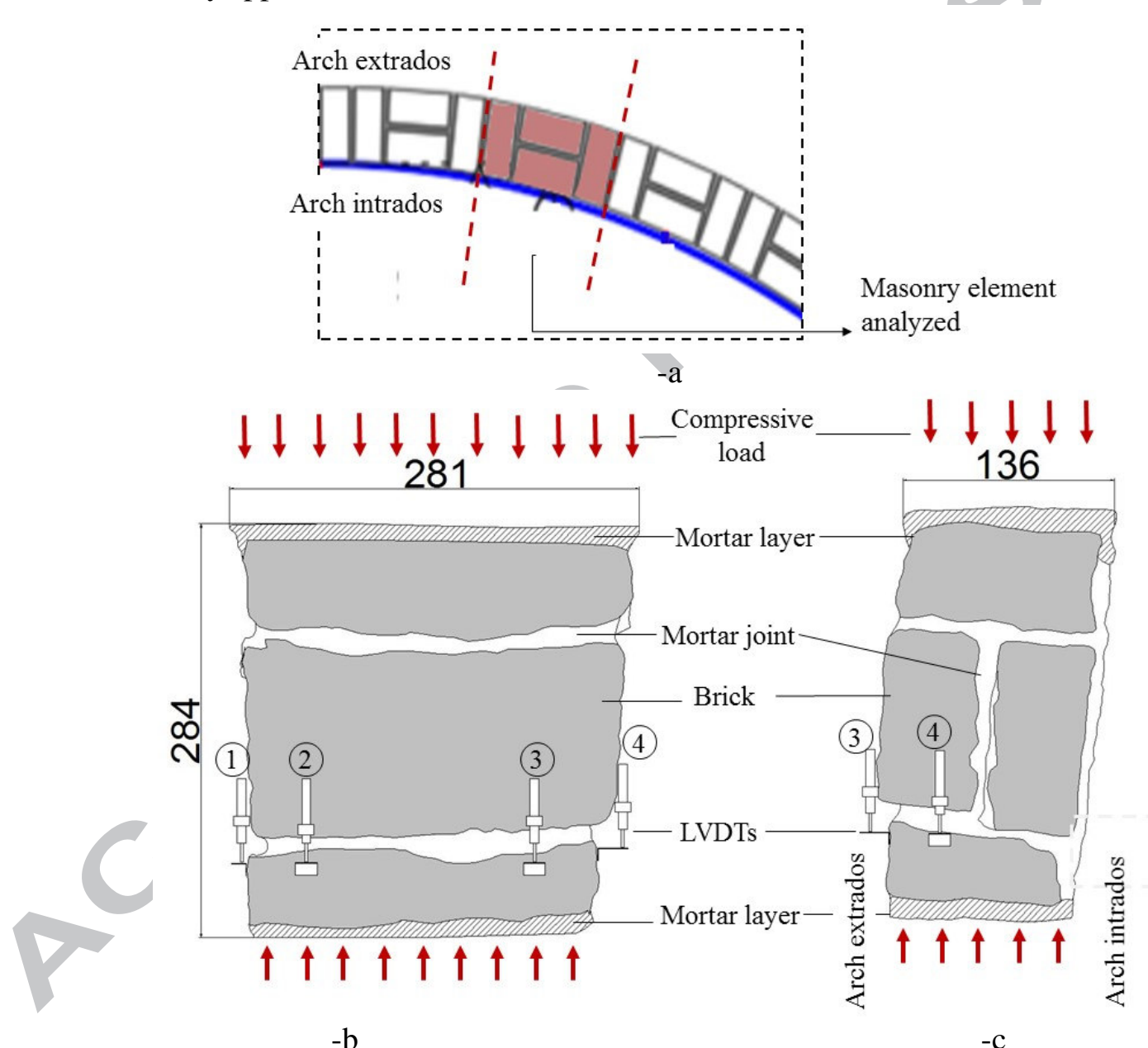

Figure 4 - Test set-up. -a: Masonry element analyzed; -b: sample front view (extrados side); -c: Sample lateral view

The failure (Figure 5b) showed the development of a crack between the vertical mortar joint and the bricks, after that the load-displacement curve showed a lower slope; when the maximum load was reached, the brick failed in compression with the detachment of a brick layer. 
Figure 6 shows the load-displacement curve. The displacement represents the average of the four vertical measurements recorded by the LVDTs applied on the mortar joint. The collapse load corresponds to a compression stress equal to about 3.5 MPa. The elastic modulus of the mortar varies between $306 \mathrm{MPa}$ and $337 \mathrm{MPa}$.

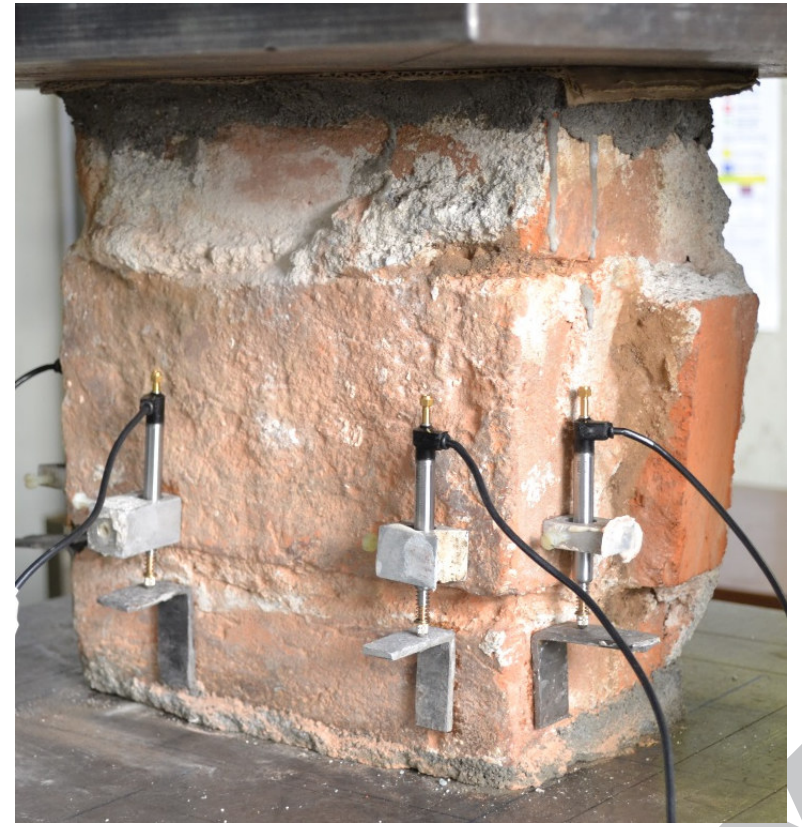

$-a$

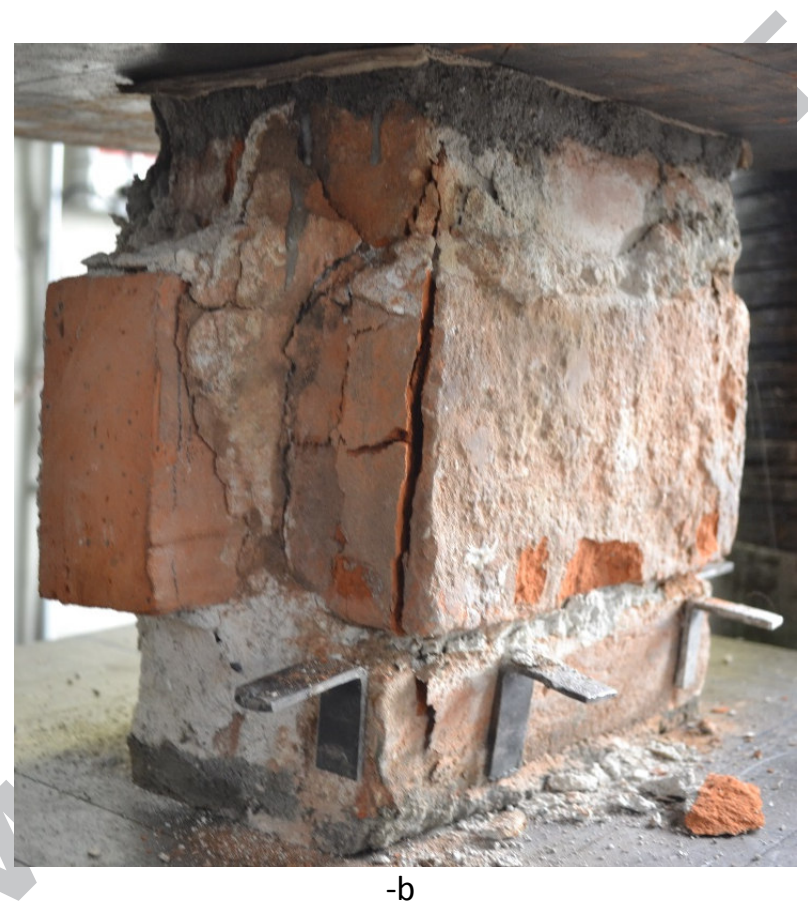

$-b$

Figure 5 - Test on masonry element: -a: Test set-up; b- Failure mode

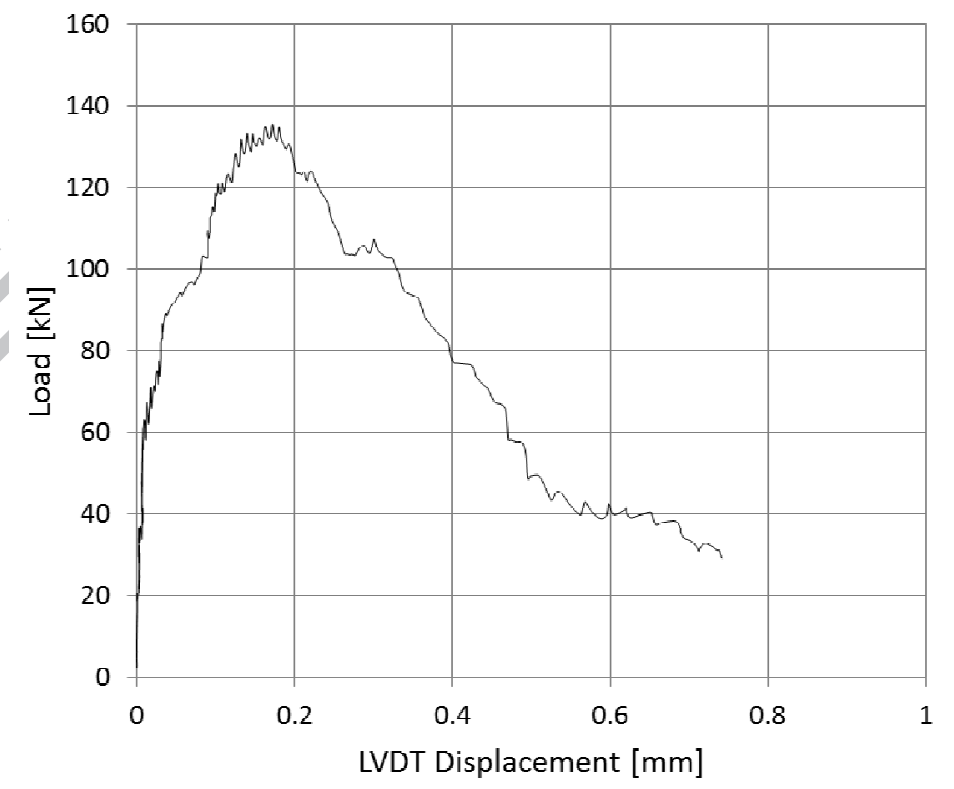

Figure 6 - Load - Displacement curve 


\subsubsection{Properties of the composite components}

The knowledge of the mechanical properties of the dry textile both in the case of FRP or TRM composites is essential to qualify the reinforcement system in the design process. For this reason, several tests on dry yarns extracted from the textile were conducted.

Tensile tests were performed on samples composed of a single yarn and steel cords according to [21][22]. Tests were carried out using a testing machine with a maximum load capacity of $2 \mathrm{kN}$. In order to avoid local damage of the specimens, fiberglass tabs were bonded to the ends of the specimens. The tests performed on dry glass yarns presented a premature failure that involved only some filaments, for this reason the yarns were impregnated with an epoxy resin that guaranteed an more homogeneous stress distribution.

Five tests were performed for each textile. The obtained average values and the coefficient of variations of mechanical properties are reported in Table 2.

Two matrices were considered. In particular, lime mortar was used to prepare the SRG and TRM systems, whereas the FRP system was made with epoxy resin. Table 3 shows the main mechanical properties and the corresponding standards used to evaluate them.

Table 2: Textiles mechanical properties.

\begin{tabular}{|c|c|c|c|}
\hline Material & $\begin{array}{c}\text { weight per unit area } \\
{\left[\mathbf{k g} / \mathbf{m}^{\mathbf{2}}\right]}\end{array}$ & $\begin{array}{c}\text { Tensile strength } \\
{[\mathbf{M P a}]}\end{array}$ & $\begin{array}{c}\text { Elastic modulus } \\
{[\mathbf{G P a}]}\end{array}$ \\
\hline \multirow{2}{*}{ Steel } & 781.3 & 1379.20 & 152.91 \\
$(5.08 \%)$ & $(2.13 \%)$ \\
\hline \multirow{2}{*}{ Glass } & 223.4 & 1442.49 & 75.43 \\
$(11.42 \%)$ & $(6.21 \%)$ \\
\hline Carbon & 319.2 & $5580 *$ & $252 *$ \\
\hline
\end{tabular}

*data from data sheet

Table 3: Mechanical properties of the mortars

\begin{tabular}{|c|c|c|c|c|}
\hline Material & $\begin{array}{c}\text { Tensile strength } \\
{[\mathrm{MPa}]}\end{array}$ & $\begin{array}{c}\text { Compressive } \\
\text { strength [MPa] }\end{array}$ & $\begin{array}{c}\text { Flexural strength } \\
{[\mathrm{MPa}]}\end{array}$ & $\begin{array}{c}\text { Elastic modulus } \\
{[\mathrm{GPa}]}\end{array}$ \\
\hline & EN 12390-6 & $\begin{array}{c}\text { EN 1015-11 } \\
\text { EN 2190 }\end{array}$ & $\begin{array}{c}\text { EN 1015 -11 } \\
\text { EN 13412 }\end{array}$ & EN 14580 \\
\hline Lime mortar & - & 7.48 & 3.16 & 6.08 \\
\hline Epoxy resin & $30.82 *$ & $65-97 *$ & $>2000 *$ & $2.89^{*}$ \\
\hline
\end{tabular}

*from technical data sheet

\subsubsection{Mechanical properties of TRM and SRG reinforcing systems}

An adequate characterization of the TRM and SRG composites requests a series of tensile and debonding tests of the system bonded on a specific masonry substrate. As highlighted in [23], these two tests are requested even for the homologation procedure of the materials.

For a complete characterization of the composite system, the following parameters must be determined: tensile behaviour, stress corresponding to the elastic phase and at failure, adhesion between textile and matrix, adhesion between the reinforcement system and the substrate, typical failure mode, debonding strength.

It is known that this results often present a great variability of the mechanical properties associated with different failure modes. A large Round Robin experimental campaign to analyze different fiber textiles and composite systems was recently performed [24]-[28]. For each material the influence of 
the following parameters was investigated: textile geometries, textile and matrix mechanical and bond properties, test set-up, specimen preparation and curing phase.

\section{- Tensile tests}

The typical stress-strain behavior of TRM and SRG under tensile tests is a tri-linear curve. The first phase represents the uncracked state in which the slope of the stress-strain curve is characterized by the elastic modulus in tension of the matrix. The second phase corresponds to the formation of cracks. In this phase there is a significant decrease of the stiffness. The length of this part of curve depends on the quality of the bond between the textile and the matrix and on the textile geometry, see for instance [29]. In the third phase, the only resistant element in the composite is the textile, therefore the slope of the curve should reflect the elastic modulus of the dry textile. This typical behavior is discussed in some detail for instance in [30][31].

Recommendations for the execution of direct tensile tests are proposed in [32]. According to this procedure a series of tensile tests was carried out. The samples were prismatic with rectangular cross section, constituted by 2 layers of mortar with a total thickness equal to $9 \mathrm{~mm}$ and a layer of textile. The width was equal to $50 \mathrm{~mm}$ and the length was $400 \mathrm{~mm}$. Fiber reinforced tabs (dimensions $60 \times 50 \times 2 \mathrm{~mm}$ ) were applied at the two opposite edges of the samples using epoxy resin. The two extremes of the specimens were fixed into the clamping wedges of a standard testing machine. The normal pressure applied in the gripping area by the wedges was such to prevent the textile from slipping out of the mortar matrix. The samples were tested after a curing period of about 50 days.

A testing machine with a load capacity of $100 \mathrm{kN}$ was used with displacement control at a rate of $0.1 \mathrm{~mm} / \mathrm{min}$ in the first phase and equal to $0.3 \mathrm{~mm} / \mathrm{min}$ in the third phase. An extensometer with a gauge length of $200 \mathrm{~mm}$ was applied in the central area of the specimen in order to measure the strains.

In the following, the results of the tests performed are briefly described. For each material a series of five tests was performed.

For TRM samples, the failure was characterized by the appearance of one or two cracks in the length of the specimen and by fibers tensile failure. The stress-strain curves showed a tri-linear behavior in which the second phase exhibited negative slope due to the formation of few cracks. It could be noted that the stiffness of the third phase is similar to the elastic modulus of the dry textile. In the first phase both the matrix and the textile are subjected to the load, but due to the low cross section area of the textile (eg: $\left.A_{\text {textile }}=2.4 \mathrm{~mm} 2 ; A_{\text {mortar }}=500 \mathrm{~mm} 2 ; A_{\text {textile }} / A_{\text {mortar }}=0.0048\right)$ it is possible to assume that the mechanical properties of this phase (elastic modulus and maximum stress) are very similar to the ones of the matrix.The elastic modulus of the first phase (6.50 GPa) could be compared to the one of the mortar while the stiffness of the third phase (78.9 GPa), in which the matrix is completed cracked, is comparable to the elastic modulus of the textile. The maximum stress reached at failure is lower with respect to the tensile strength reported in Table 2 due to the failure mode that was characterize by a slippage phenomenon. The collapse is due to slippage between textile and matrix and to the final failure of the external filaments of the yarns. The typical telescopic failure mode was noted; only the sleeve filaments were impregnated by the mortar while the internal ones presented a slippage due to the pull-out force.

This behavior was highlighted also in [28], that compared tests performed by many laboratories on different TRM systems with glass fiber textiles.

During the tests on SRG specimens, the development of two or three cracks was noted and the cords failed close to the main crack. In some cases, the failure is limited to some cords while one or two 
were subjected to slippage phenomena. Due to this failure mode, the maximum stress reached (1276 MPa) was slightly lower than the tensile strength of the dry textile. The last phase of the tests was characterized by a lower stiffness due to the yielding of the steel cords. The elastic modulus of the first phase $(7.47 \mathrm{GPa}$ ) could be compared to the one of the mortar and to the one reached in the tests on TRM system that was constituted by the same matrix. The stiffness of the third phase (172.2 $\mathrm{GPa}$ ) was comparable to the elastic modulus of the dry textile.

In [30] a similar behaviour was described. The failure was due to the rupture of few lateral cords without sliding or telescopic failure. In some cases, the recovery of the elastic deformation of the steel cords caused the detachment of small parts of the mortar.

In Table 4 the average results of the main mechanical parameters and the coefficients of variation are reported. The parameters were derived dividing the loads by the section of the textile. Only for the first phase, in which the mortar is un-cracked, the tensile stress $\left(\sigma_{T 1}^{*}\right)$ and the elastic modulus $\left(E_{1}^{*}\right)$ were also referred to the composite cross section, in order to compare these values with the mechanical parameters of the mortar.

Figure 7 shows the stress-strain curves obtained for the TRM and SRG reinforcement systems.
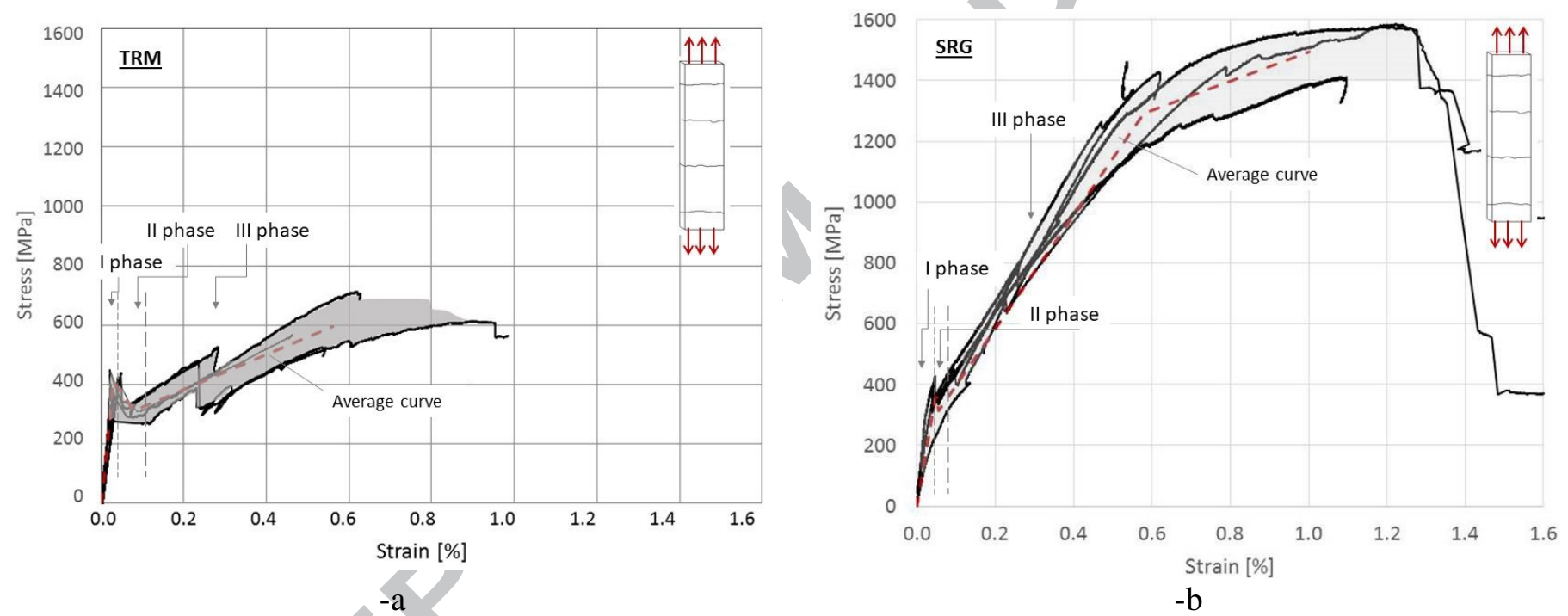

Figure 7 - Tensile stress-strain behavior. -a: TRM. -b: SRG.

\section{- Bond tests}

The bond properties of TRM and SRG systems were also investigated in the literature. Few data referred to systems composed by glass textile are available. On the contrary the SRG systems were deeper analyzed.

An experimental campaign including pull-off and shear tests was performed to investigate the bond properties of the TRM system applied on masonry.

Three pull-off tests were performed, according to [33], on masonry elements extracted from the vault after the collapse of the structure. In two cases the part of reinforcement subjected to the perpendicular load was applied on the brick; in one case also the mortar joint of the masonry substrate was included. In the first configuration a maximum stress of $0.17 \mathrm{MPa}$ was reached, in the second one the adhesion properties were lower with a maximum stress of $0.05 \mathrm{MPa}$. In all cases the failure was located at the interface between the substrate and the TRM system. This failure shows a 
good adhesion between the two mortar layers of the reinforcement. Due to the poor mechanical properties of the lime mortar, the failure was adhesive, see [34].

Five shear tests were performed according to [32]. The TRM system was applied on masonry elements constituted by five bricks and four mortar joints. The bricks were characterized by an average compressive strength equal to $20 \mathrm{MPa}$, the matrix was a M5 lime mortar.

The reinforcement was applied on the larger face of the element, the bond length and width were equal to $260 \mathrm{~mm}$ and $100 \mathrm{~mm}$ respectively. A part of textile with a length of $300 \mathrm{~mm}$ remained not impregnated and was used to connect the upper part of the sample to the testing machine.

An uniaxial testing machine with a load capacity of $250 \mathrm{kN}$ was used. The samples were located in a rigid frame in order to avoid any displacement and rotation during the tests. At the end of the dry textile two FRP tabs were glued and the tabs were clamped in two steel plates connected to a spherical joint. The tests were performed under displacement control at a rate equal to $0.2 \mathrm{~mm} / \mathrm{min}$. Two linear variable displacement transducers (LVDTs) were located on the masonry surface close to the edge of the bonded area to measure the slip between the textile and the matrix. The points of the LVDTs were positioned on a thin aluminum plate that was attached to the textile transversal yarn adjacent to the beginning of the bonded area. In Figure 8 the test set-up and the typical failure mode are reported.

The failure mode was characterized by textile slippage within the mortar matrix; in some cases some cracks appeared on the external mortar layer. Some external filaments of the yarns failed during the slipping while the internal ones slipped because not well impregnated by the matrix. This telescopic failure mode was similar to the one described for the tensile tests.

The average maximum peak stress in the textile was equal to $335 \mathrm{MPa}$, with a minimum value equal to $314 \mathrm{MPa}$ and a maximum of $350 \mathrm{MPa}$ and the correspondent average slip was equal to $0.64 \mathrm{~mm}$ (Figure 9). Obviously, due to the failure mode, the maximum stress was very low when compared to the textile tensile strength.

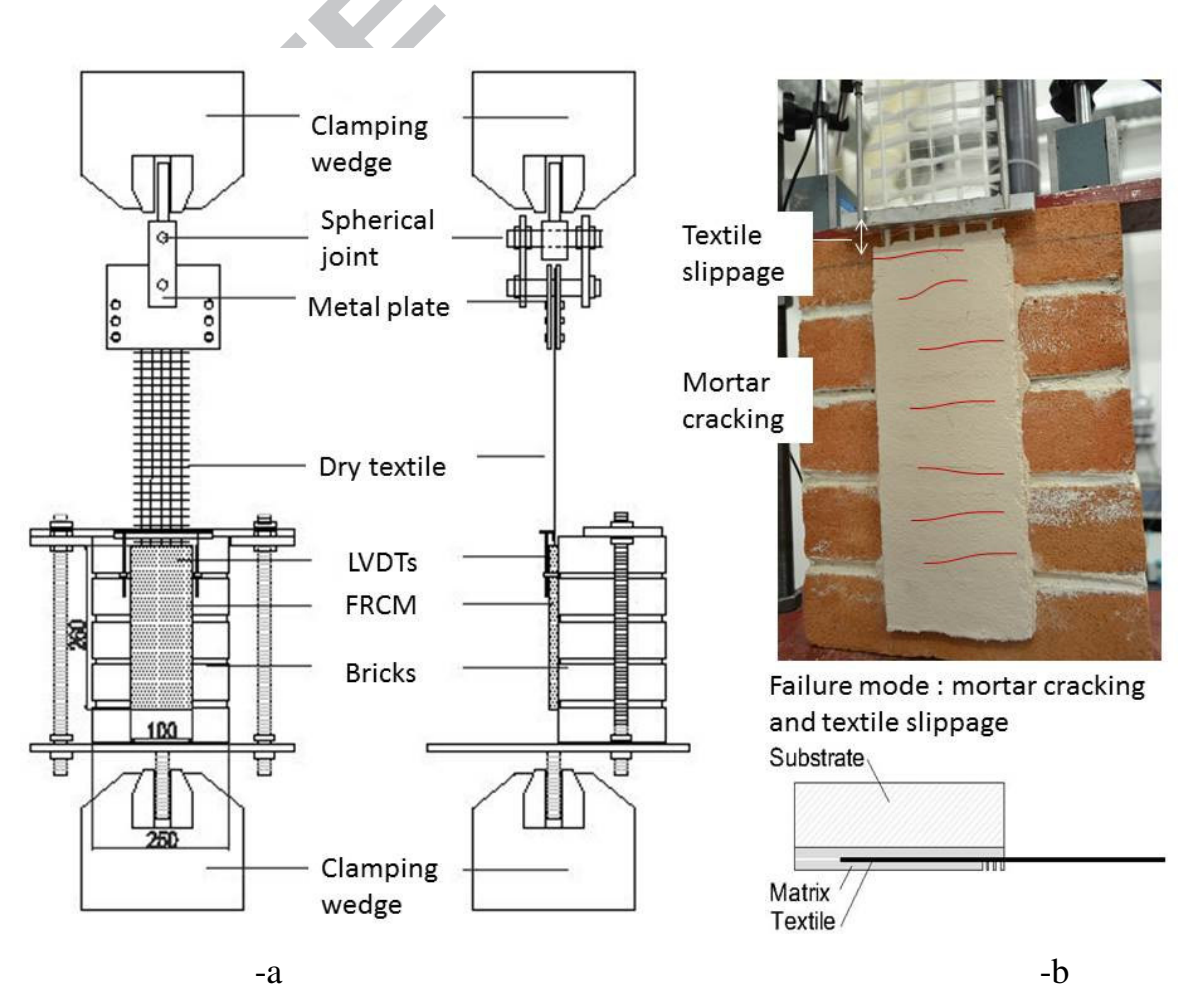

Figure 8: Shear test on TRM system. -a: test set-up. -b: failure mode 


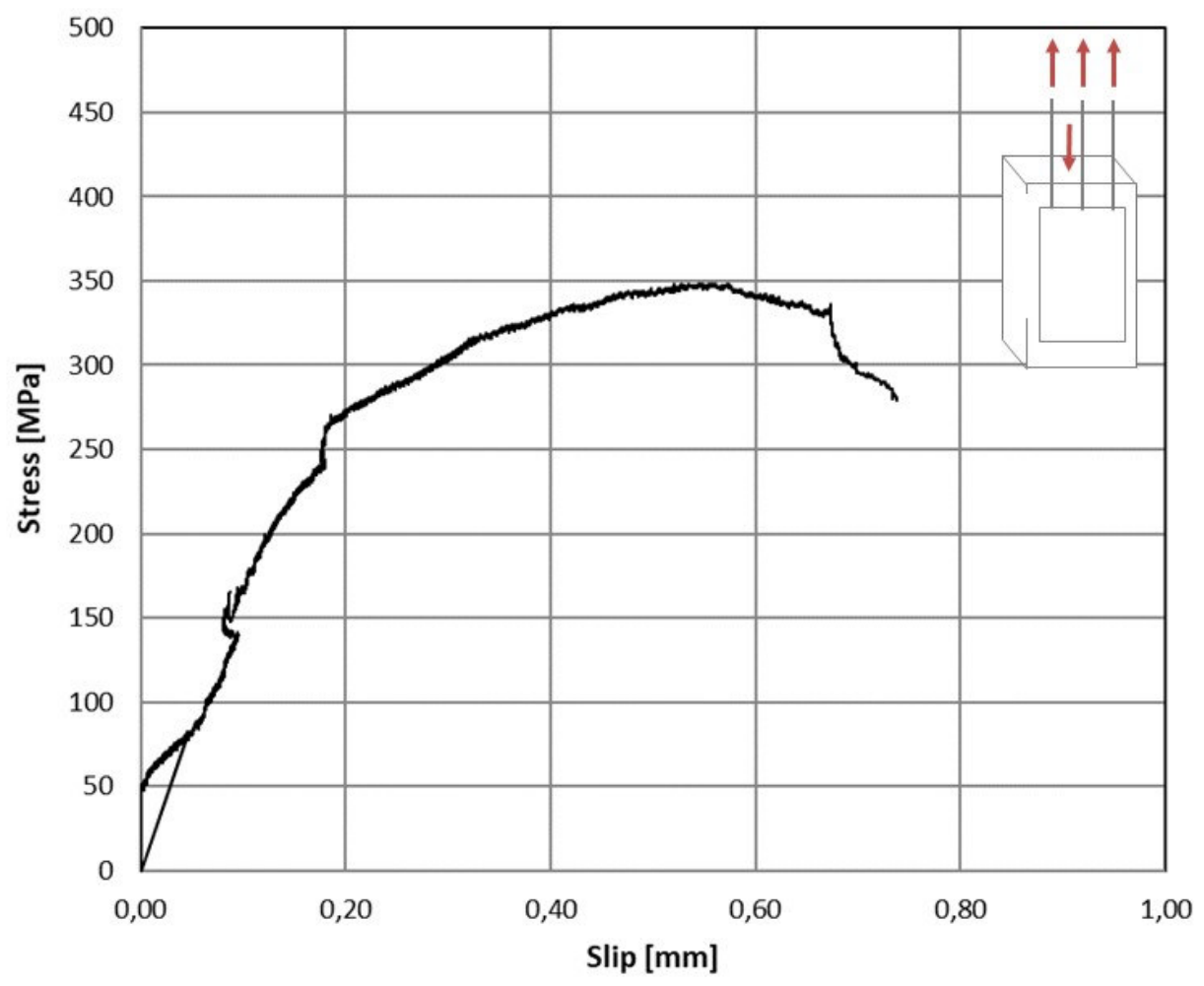

Figure 9 - Stress-slip curves: TRM system

The bond properties of SRG systems applied on masonry structures were investigated in [24][35][36]. The tests performed on a SRG system similar to the one involved in this project were characterized by failure at the interface between textile and matrix or by textile slippage whitin the mortar layer. The maximum stress reached in the textile varied from $600 \mathrm{MPa}$ to $800 \mathrm{MPa}$.

\subsubsection{Mechanical properties of FRP reinforcing systems}

A series of tensile tests were performed on 8 FRP samples. Mechanical parameters were computed according to [37].

The samples were cut from a panel made with three layers of carbon textile and epoxy resin. The nominal dimensions of each specimen were $250 \times 20 \times 2 \mathrm{~mm}$. At the extremities of the samples, GFRP tabs were glued in order to guarantee an homogeneous stress distribution. A testing machine with a load capacity of $100 \mathrm{kN}$ was used under displacement control at a rate of $1 \mathrm{~mm} / \mathrm{min}$. An extensometer with a gauge length of $50 \mathrm{~mm}$ was applied in the central area of the specimen and it was removed when a load equal to half of the failure load was reached. An almost linear elastic behavior up to failure was recorded.

The average maximum stress reached (Table 4) was equal to $4174.3 \mathrm{MPa}$ and the average elastic modulus was $258.8 \mathrm{GPa}$, with a coefficient of variation equal to $5.6 \%$ and $2.5 \%$ respectively.

The perpendicular bond properties of the FRP system applied on masonry elements were investigated using pull-off tests while the shear bond properties were analytically estimated. 
The most common phenomenon influencing the effectiveness of the FRP repair of masonry structures is debonding of the reinforcement system from the substrate. This typical failure mode was experimentally highlighted by many experimental researches, see for instance [38]-[41].

FRP systems quite similar to the one used in this project applied on a masonry substrate were characterized by a maximum debonding strength ranging between $700 \mathrm{MPa}$ and $950 \mathrm{MPa}$.

On the other hand, the maximum transferable load between the textile and the substrate could be also analytically estimated, taking into account the specific mechanical properties of materials analyzed. In [42] a formulation based on the mechanical properties of bricks and reinforcement is proposed to compute the fracture energy and the maximum transferable load.

According to this bond strength model the maximum stress reached in the FRP is equal to 378.8 $\mathrm{MPa}$. This value is lower than the ones obtained in the literature probably because of the low mechanical properties of the ancient bricks of the substrate. Considering the reinforcement area applied on the masonry vault, the maximum load transferable by the FRP reinforcement was 6.25 $\mathrm{kN}$.

Three pull-off tests were carried out according to [33] on masonry elements extracted from the vault after the collapse of the structure. A maximum stress of $0.20 \mathrm{MPa}$ was reached. In all the cases the failure was cohesive and located in the substrate.

Table 4: Tensile tests on TRM and SRG systems.

\begin{tabular}{|c|c|c|c|c|c|c|c|c|c|}
\hline \multirow[b]{2}{*}{ Material } & \multicolumn{8}{|c|}{ Tensile test } & Shear test \\
\hline & $\begin{array}{c}\mathrm{E}_{1} \\
{[\mathrm{GPa}]}\end{array}$ & $\begin{array}{c}\mathrm{E}_{3} \\
{[\mathrm{GPa}]}\end{array}$ & $\begin{array}{c}\sigma_{T 1} \\
{[\mathrm{MPa}]}\end{array}$ & $\begin{array}{c}\sigma_{T 2} \\
{[\mathrm{MPa}]}\end{array}$ & $\begin{array}{c}\sigma_{u} \\
{[\mathrm{MPa}]}\end{array}$ & $\begin{array}{l}\sigma_{\text {yield }} \\
{[\mathrm{MPa}]}\end{array}$ & $\begin{array}{c}\mathrm{E}_{1}^{*} \\
{[\mathrm{GPa}]}\end{array}$ & $\begin{array}{c}\sigma_{T 1}^{*} \\
{[\mathrm{MPa}]}\end{array}$ & $\begin{array}{c}\sigma_{d e b} \\
{[\mathrm{MPa}]}\end{array}$ \\
\hline TRM & $\begin{array}{l}1213.39 \\
(19.3 \%)\end{array}$ & $\begin{array}{c}78.90 \\
(9.7 \%)\end{array}$ & $\begin{array}{l}414.71 \\
(9.8 \%)\end{array}$ & $\begin{array}{c}312.56 \\
(12.7 \%)\end{array}$ & $\begin{array}{c}595.26 \\
(14.0 \%)\end{array}$ & - & $\begin{array}{c}6.50 \\
(21.4 \%)\end{array}$ & $\begin{array}{c}2.08 \\
(9.4 \%)\end{array}$ & $\begin{array}{c}335 \\
(9.2 \%)\end{array}$ \\
\hline SRG & $\begin{array}{c}654.77 \\
(27.5 \%)\end{array}$ & $\begin{array}{c}172.22 \\
(15.7 \%)\end{array}$ & $\begin{array}{c}361.40 \\
(12.3 \%)\end{array}$ & $\begin{array}{l}314.10 \\
(12.3 \%)\end{array}$ & $\begin{array}{c}1493.15 \\
(5.5 \%)\end{array}$ & $\begin{array}{c}1293.08 \\
(6.6 \%)\end{array}$ & $\begin{array}{c}7.47 \\
(27.1 \%)\end{array}$ & $\begin{array}{c}3.54 \\
(12.4 \%)\end{array}$ & $600-800 *$ \\
\hline FRP & $\begin{array}{l}258.80 \\
(2.5 \%)\end{array}$ & - & & - & $\begin{array}{c}4174.31 \\
(5.6 \%)\end{array}$ & - & - & - & $378.8 * *$ \\
\hline
\end{tabular}

* From literature

** Analytically computed according to [42]

Note: $\mathrm{E}_{1}^{*}$ and $\sigma_{T 1}^{*}$ were computed with respect to the cross section area of the mortar.

\subsection{In-situ experiments: test set-up}

The two arches and the three vaults were subjected to a concentrated vertical load applied at a distance of $556 \mathrm{~mm}$ from the left abutment (approximately one fourth of the span). The load was applied using a hydraulic manual jack connected to a load cell with a maximum capacity of $100 \mathrm{kN}$. The jack was located on a contrast beam. In Figure 10 the test set-up is shown. A hole in the arch allowed the connection of the jack with a contrast element located at the extrados with a steel bar (Figure 10-b). The load was monotonically applied but a series of two or three load-unload cycles were applied before reaching the collapse of the structure in order to equally distribute the load and to evaluate possible residual deformation in the structure.

The test on the unreinforced barrel vault (U_V) was not performed with a hydraulic jack, because of the very low carrying capacity expected. A series of masses having weight equal to $0.07 \mathrm{kN}$ and 
$0.04 \mathrm{kN}$ were manually added on a plate in order to apply a small increasing concentrated load positioned at one fourth of the span of the vault.

Four displacement transducers were used to measure the vertical displacements. As showed in Figure 2 two instruments were installed at about one fourth of the span (on both sides to eventually monitor torsion) and one in the middle, in correspondence of the crown. Due to non perfect regularity of the structure and to the different location of the bricks, the position of the LVDTs was not exactly the same in the different tests. In Table 5 the location of the LVDTs is reported as the angle with respect to the horizontal line. The arch and the vaults were represented as a bow of circumference with a radius equal to $1995 \mathrm{~mm}$, the angle were computed with respect to the diameter of the circumference.

During the tests, a visual inspection was also performed in order to identify cracks in the mortar and in the substrate, hinges formation and debonding phenomena.

Table 5 - LVDTs location

\begin{tabular}{|c|c|c|c|c|}
\hline \multirow{2}{*}{ Structure } & \multicolumn{4}{|c|}{ LVDTs } \\
\cline { 2 - 5 } & $\mathbf{d}_{\mathbf{1}}$ & $\mathbf{d}_{\mathbf{2}}$ & $\mathbf{d}_{\mathbf{3}}$ & $\mathbf{d}_{\mathbf{4}}$ \\
\hline U_A & 117.06 & 89.07 & 66.55 & 66.55 \\
\hline SRG_A & 117.06 & 89.07 & 66.55 & 66.55 \\
\hline U_V & 113.98 & 89.78 & 66.01 & 66.01 \\
\hline FRP_V & 113.98 & 90 & 66.01 & 66.01 \\
\hline TRM_V & 113.98 & 90 & 66.01 & 66.01 \\
\hline
\end{tabular}

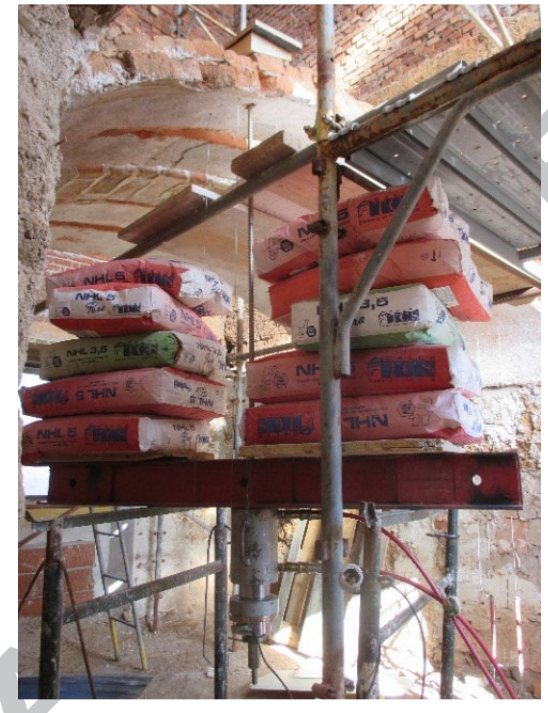

$-\mathrm{a}$

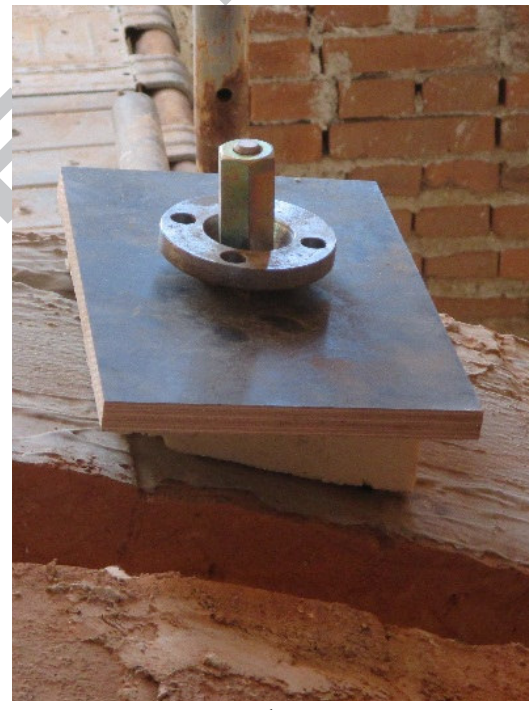

$-b$

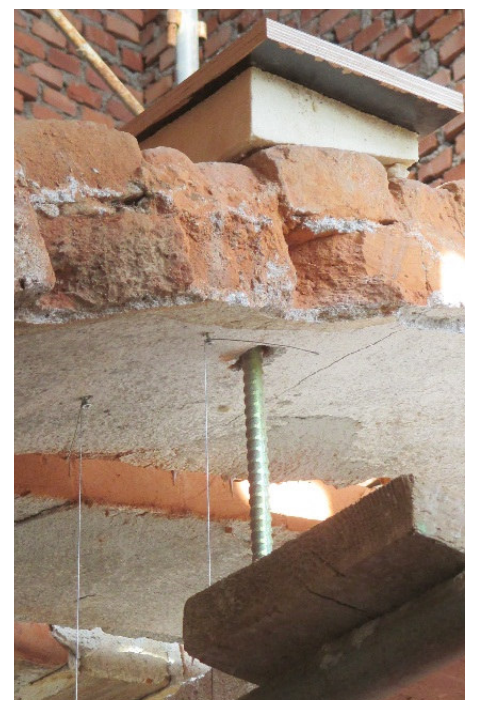

$-\mathrm{c}$

Figure 10: details of the test set-up. $-\mathrm{a}$ : contrast beam. $-\mathrm{b}$ : contrast element at the extrados. $-\mathrm{b}$ : steel bar used to applied the load and vertical displacement transducers

\subsection{Experimental results}

In Table 6 a synopsis of the most important experimental results obtained is reported and includes maximum loads, the correspondent displacement, stiffness and ductility factor. The stiffness was evaluated in the linear part of the load-displacement curve recorded at the loaded point (average between the displacement recorded by LVDTs $\delta_{3}$ and $\delta_{4}$ ) without considering the influence of the 
first non-linear branch. A ductility factor was computed as the ratio between the displacement reached at the maximum load and the one corresponding to the linear elastic limit determined from the load-displacement curve [14]. Also in this case the average between the displacement recorded by LVDTs $\delta_{3}$ and $\delta_{4}$ was considered. In the case of the barrel vault, the collapse happened immediately after the application of the last mass, for this reason the displacements reported in Table 5 are referred to a load of $0.35 \mathrm{kN}$ and not to the maximum load. In Figures 11, 12 and 16 the load-displacement curves were reported.

Table 6: Experimental results

\begin{tabular}{|c|c|c|c|c|c|c|c|}
\hline \multirow{2}{*}{ Structure } & \multirow{2}{*}{$\begin{array}{c}\text { Collapse load } \\
\mathbf{F}_{\max }[\mathbf{k N}] \\
\end{array}$} & \multicolumn{4}{|c|}{ Displacements at collapse $[\mathrm{mm}]^{* *}$} & \multirow{2}{*}{$\begin{array}{l}\text { Stiffness } \\
{[\mathrm{N} / \mathrm{mm}]}\end{array}$} & \multirow{2}{*}{$\begin{array}{l}\text { Ductility } \\
\text { factor [-] }\end{array}$} \\
\hline & & $d_{1}$ & $\mathrm{~d}_{2}$ & $\mathrm{~d}_{3}$ & $\mathrm{~d}_{4}$ & & \\
\hline $\mathbf{U} \mathbf{U}_{-} \mathbf{A}$ & 2.08 & 2.36 & 2.16 & -3.89 & -3.58 & 1281.74 & 3.25 \\
\hline SRG_A & 8.83 & 0.71 & 0.49 & -3.53 & -3.32 & 4187.61 & 1.85 \\
\hline $\mathbf{U}_{-} \mathbf{V}$ & 0.39 & $-0.42 *$ & $-5.69 *$ & $-6.41 *$ & $-4.37 *$ & 324.24 & - \\
\hline FRP_V & 1.54 & 4.54 & 4.42 & -5.89 & -6.02 & 344.72 & 1.60 \\
\hline TRM_V & 2.17 & 2.54 & 4.40 & -3.67 & -4.08 & 1181.82 & 3.19 \\
\hline
\end{tabular}

* the displacements are referred to a load equal to $0.35 \mathrm{kN}$

** negative values represent downward movements

\subsubsection{Unreinforced (U_A) and SRG reinforced arch (SRG_A)}

In this section the results obtained for the unreinforced and reinforced arches are described and analyzed.

The unreinforced arch exhibited a collapse mechanism with the classic formation of four alternative hinges, two at the intrados and two at the extrados. In Figure 11 the experimental curves are reported, together with the vertical displacement recorded by each of the four LVDTs plotted with respect to the applied load.

The first hinge appeared at the extrados, under the concentrated load, at a load approximately equal to $1.9 \mathrm{kN}$ and even the second hinge appeared at the extrados in correspondence of the right abutment. When the second hinge appeared the load started to decrease, with a first vertical drop and a subsequent fast decreasing branch characterized by a significant increment of the vertical displacement. In this phase also the third and fourth hinges appeared. The third one located at the intrados in an almost symmetrical position with respect to the first one, with an angle $\alpha=98^{\circ}$ with respect to the horizontal line. The last hinge appeared at the left abutment with a complete detachment from the left springing.

Figure 12 shows the experimental load-displacement curves obtained for the arch reinforced with the SRG system (SRG_A). Five loading-unloading cycles were applied during the elastic phase, with a maximum residual displacement equal to $0.35 \mathrm{~mm}$. The stiffness of the re-load phase was very similar to the initial one, namely equal to $3938.9 \mathrm{~N} / \mathrm{mm}$.

The presence of the SRG reinforcement slightly modified the collapse mechanism of the arch. A first hinge appeared at the loaded section when the maximum load was reached. The test continued with a slow decrease of the load and an increment in the vertical displacement, a second hinge appeared in correspondence of the left abutment. Collapse was characterized by a complete detachment of the abutment element from the lateral wall, with concentrated masonry crushing in 
the loaded section. Only at collapse, a local debonding of the reinforcement from the substrate occurred near the right abutment. No meaningful damages of the SRG were observed (Figure 13).

In Figure 14 where the arch was represented as a bow of circumference with a radius equal to 1995 $\mathrm{mm}$, the order of the hinges appearance and the corresponding angle respect to the horizontal line is reported.

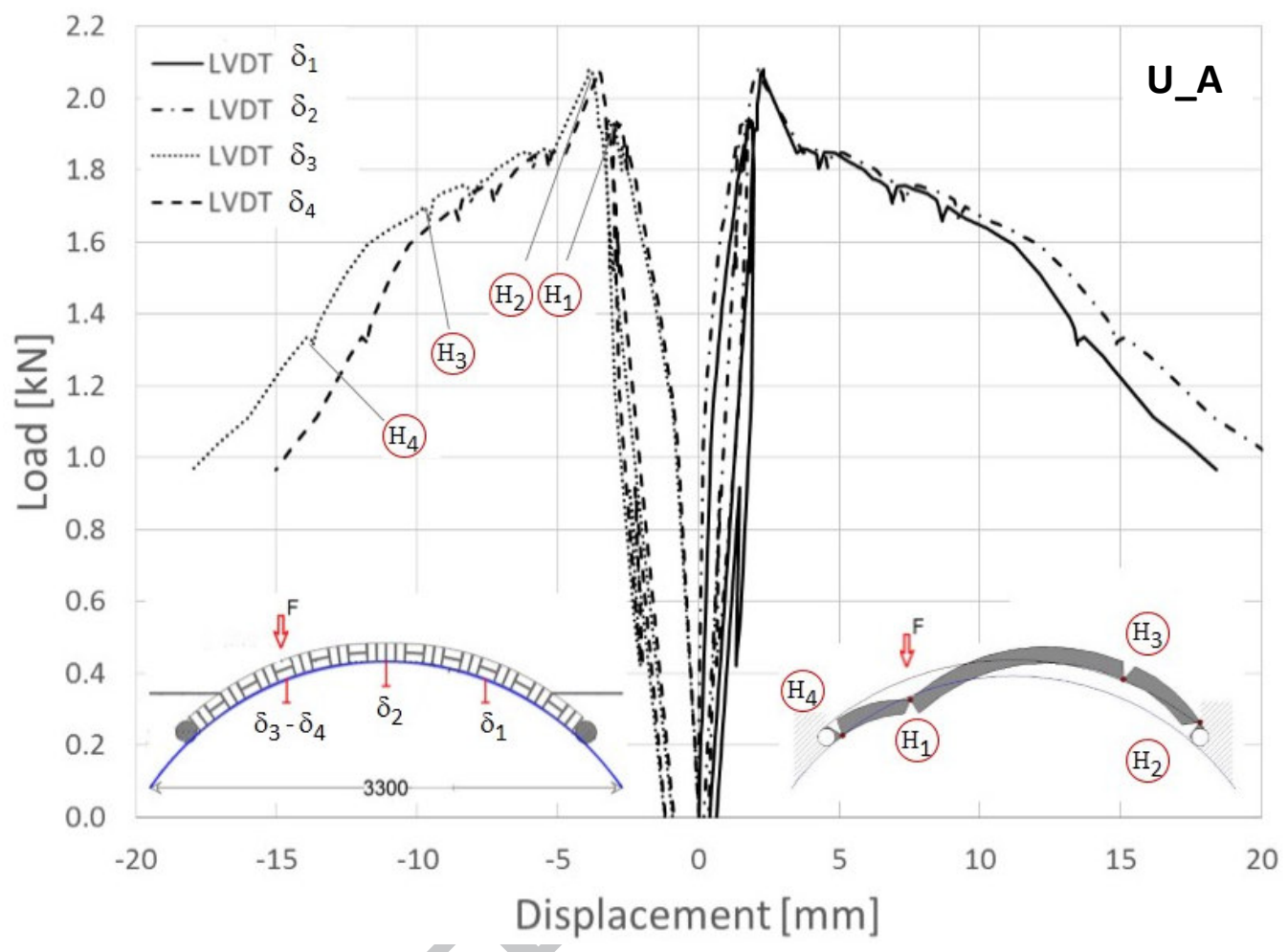

Figure 11: U_A unreinforced arch, load-displacement behavior. 


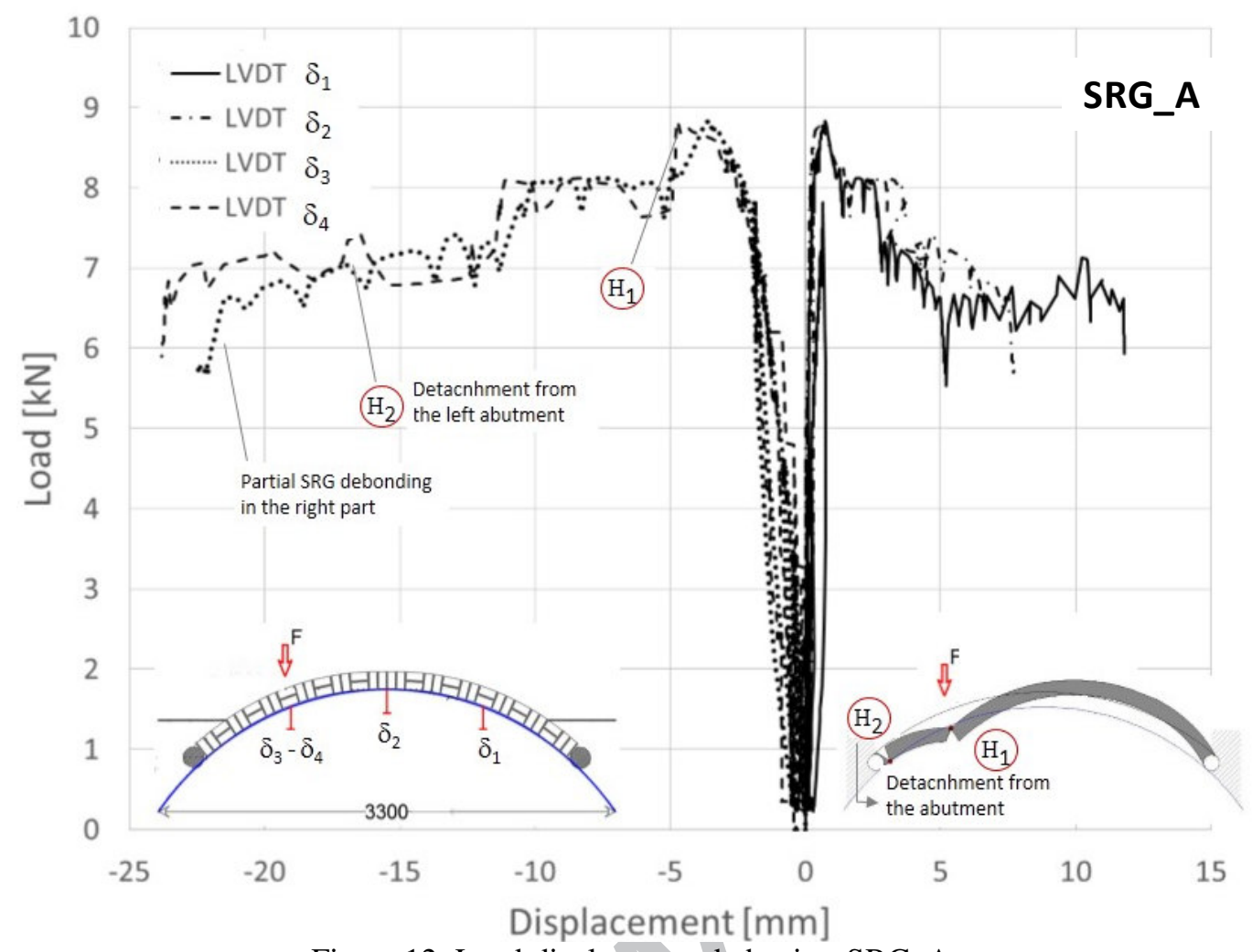

Figure 12: Load-displacement behavior, SRG_A.

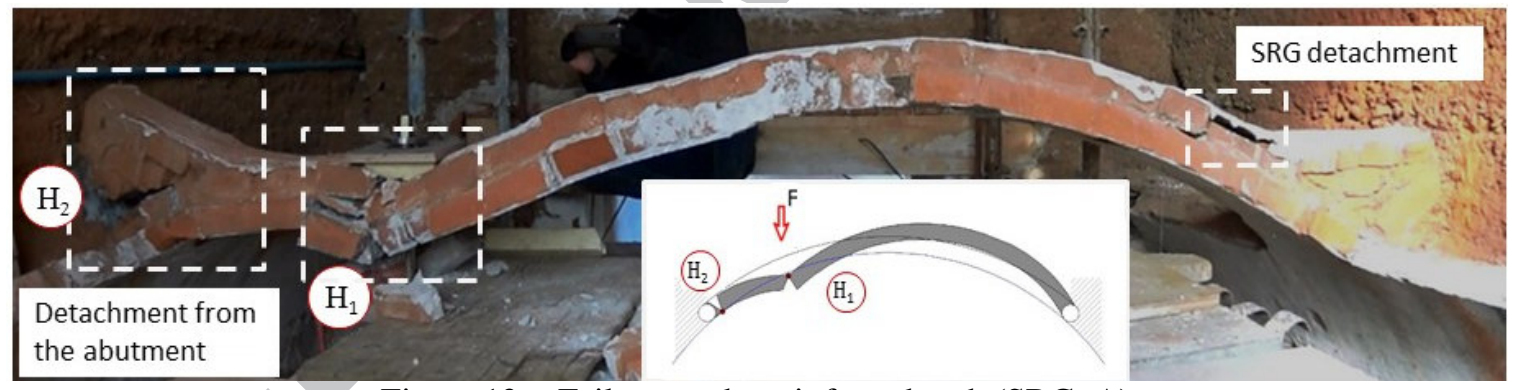

Figure 13: : Failure mode: reinforced arch (SRG_A)

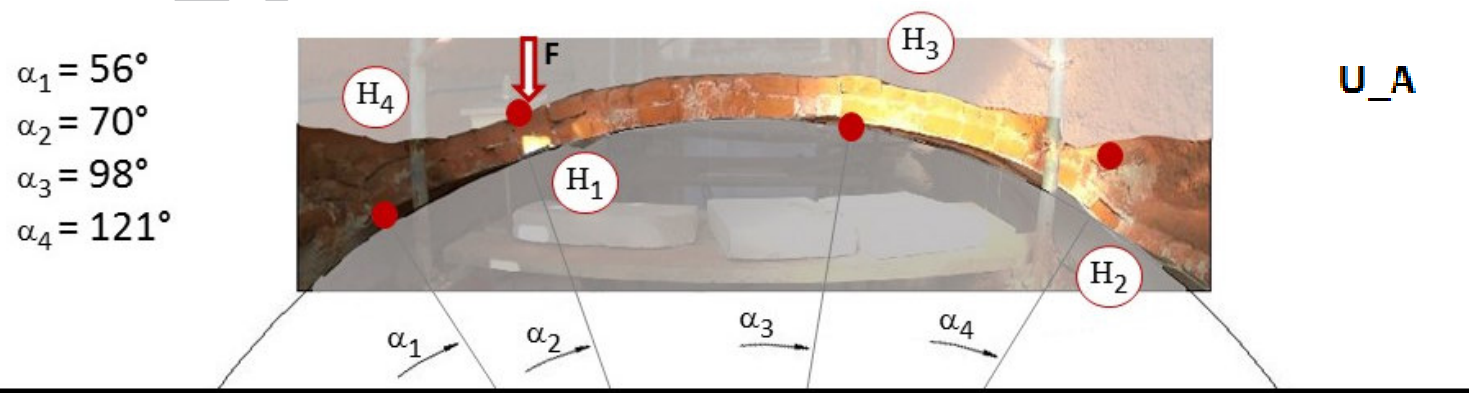




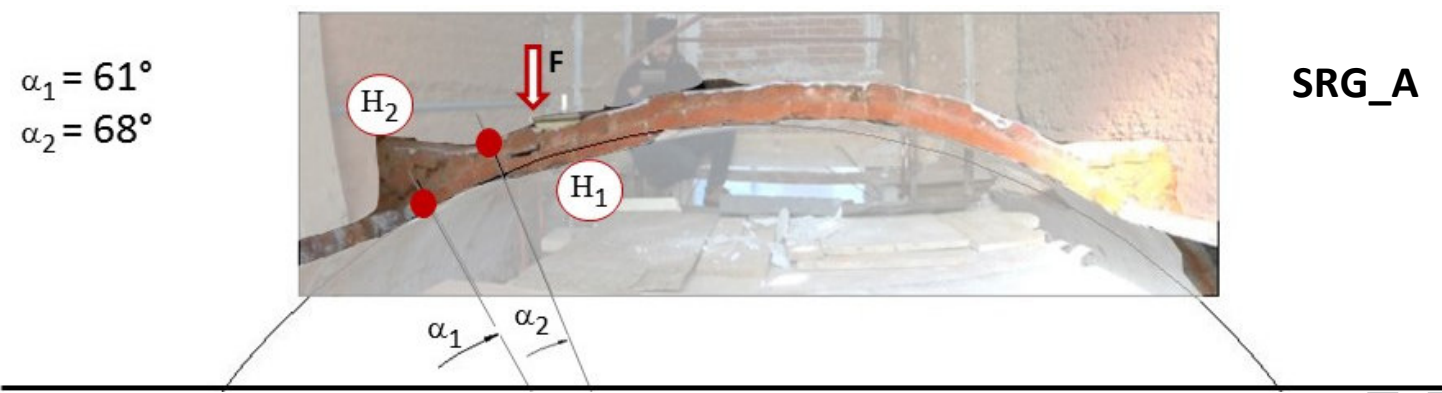

$-b$

Figure 14: Order of the hinges opening, -a: unreinforced arch (U_A); -b: SRG reinforced arch (SRG_A)

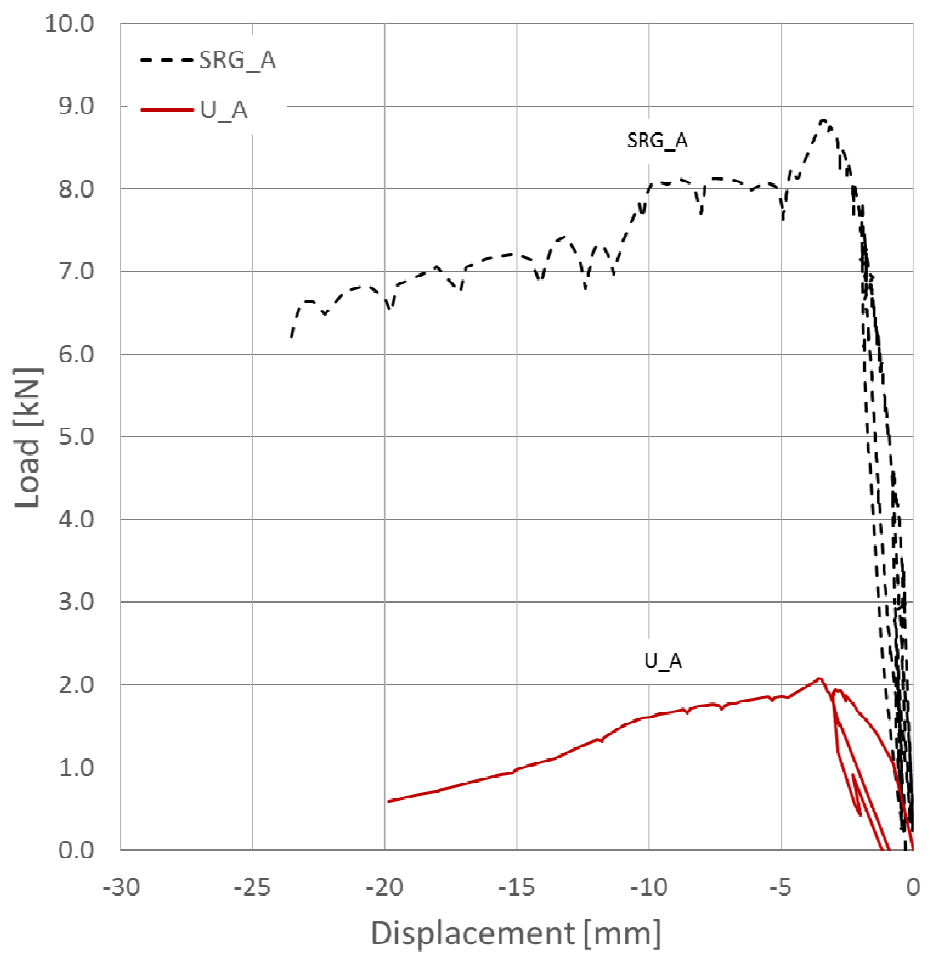

$-\mathrm{a}$
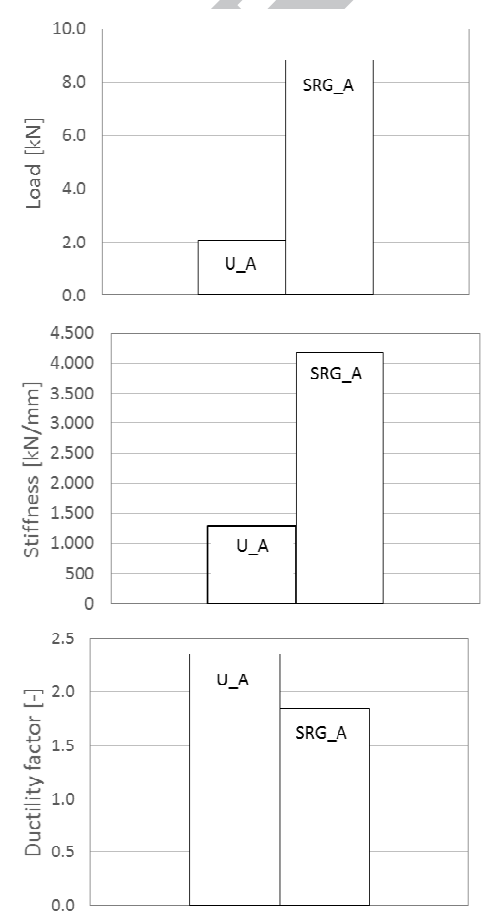

$-b$

Figure 15: Comparison between unreinforced (U_A) and reinforced (SRG_A) arches. -a: load-displacement curves. -b: load, stiffness and kinematic ductility comparison

In Figure 15 a comparison between the tests performed on the unreinforced and reinforced arches is reported. The maximum load reached on the unreinforced arch was increased by 4 times by the contribution of SRG system. On the opposite, the application of SRG caused a relevant increment in the stiffness of the structure, roughly by a factor 3 . The ductility of the reinforced structure seems to be lower, but it should be considered that the elastic phase of the unreinforced structure was very small, whereas SRG_A exhibited a behavior almost linear up to the peak load. In the decreasing phase the reinforced structure was able to keep a high load -fairly constant- for larger displacement values, which demonstrates the satisfactory ductility of the system.

\subsubsection{Unreinforced vault (U_V), FRP and TRM reinforced vaults (FRP_V and TRM_V)}

The unreinforced vault exhibited a collapse mechanism with the classic formation of four alternative hinges, two at the intrados and two at the extrados. 
The failure of the masonry vault U_V occurred suddenly, as expected in correspondence of small displacements and just after the maximum load was reached. The first hinge appeared at the extrados, under the concentrated load, the second one at the intrados in a symmetrical position, with an angle $\alpha=105^{\circ}$ respect to the horizontal line. The third and fourth hinges appeared at the left and right abutments.

Figure 16 shows the load-displacement curves of the vaults reinforced with FRP (Figure 16-a) and TRM (Figure 16-b) systems.

The FRP_V showed a linear elastic behavior up to the maximum load, after a first drop in the load the test continued with a decrease in the applied force and an increment of the displacement, in particular in the section where the load was applied. In this phase a loading-unloading cycle was applied, the structure presented a residual deformation corresponding to $60 \mathrm{~mm}$ in the section subjected to the load and to $27 \mathrm{~mm}$ at the opposite quarter of the span. As expected, the second load cycle was characterized by a lower stiffness compared to the elastic one $(27 \mathrm{~N} / \mathrm{mm}$ against 344.72 $\mathrm{N} / \mathrm{mm}$ ) of the first cycle.

The failure mode was characterized by the formation of a first hinge in correspondence to the applied concentrate load, that corresponds to the drop in the load carrying capacity. The FRP prevented the appearance of the hinge at the extrados at the opposite quarter of the span. The second hinge appeared at the left abutment with a complete detachment. The test continued with an increment of the displacement up to the collapse that was caused by the detachment from the right abutment and the debonding of the FRP reinforcement in the right part of the vault.

In Figure 17 the order of the hinges appearance and the correspondent angle with respect to the horizontal line is reported, the vault was represented as a bow of circumference with a radius equal to $1995 \mathrm{~mm}$. The structural element and the reinforcement system were not well connected to the abutment, that could not prevent a bending phenomenon, for this reason the collapse was not correlated to the typical formation of four hinges. Figure 18 shows the failure mode.

The test performed on TRM_V was characterized by four loading-unloading cycles. The first two cycles were performed in the elastic phase and no relevant residual displacements were measured (the maximum residual displacement after the second unload was equal to $0.22 \mathrm{~mm}$ ). The first hinge appeared in correspondence to the applied load, at a load approximately equal to $1.8 \mathrm{kN}$. Then, a new unloading-loading cycle was applied and the maximum residual displacement observed was equal to $0.65 \mathrm{~mm}$. The last load phase exhibited a lower stiffness equal to $451 \mathrm{~N} / \mathrm{mm}$. At a load equal to $2.1 \mathrm{kN}$ the second hinge appeared at the extrados at about $3 / 4$ of the total span $\left(\alpha=106^{\circ}\right)$, and the reinforced mortar cracked. After a drop in the load, the test continued with a relevant increment in the vertical displacement. The structure collapsed for the formation of other two hinges at the abutments. The glass textile collapse in correspondence of the second hinge due to slippage phenomena and tensile rupture of the external filaments of the yarns (see Figure 19). 

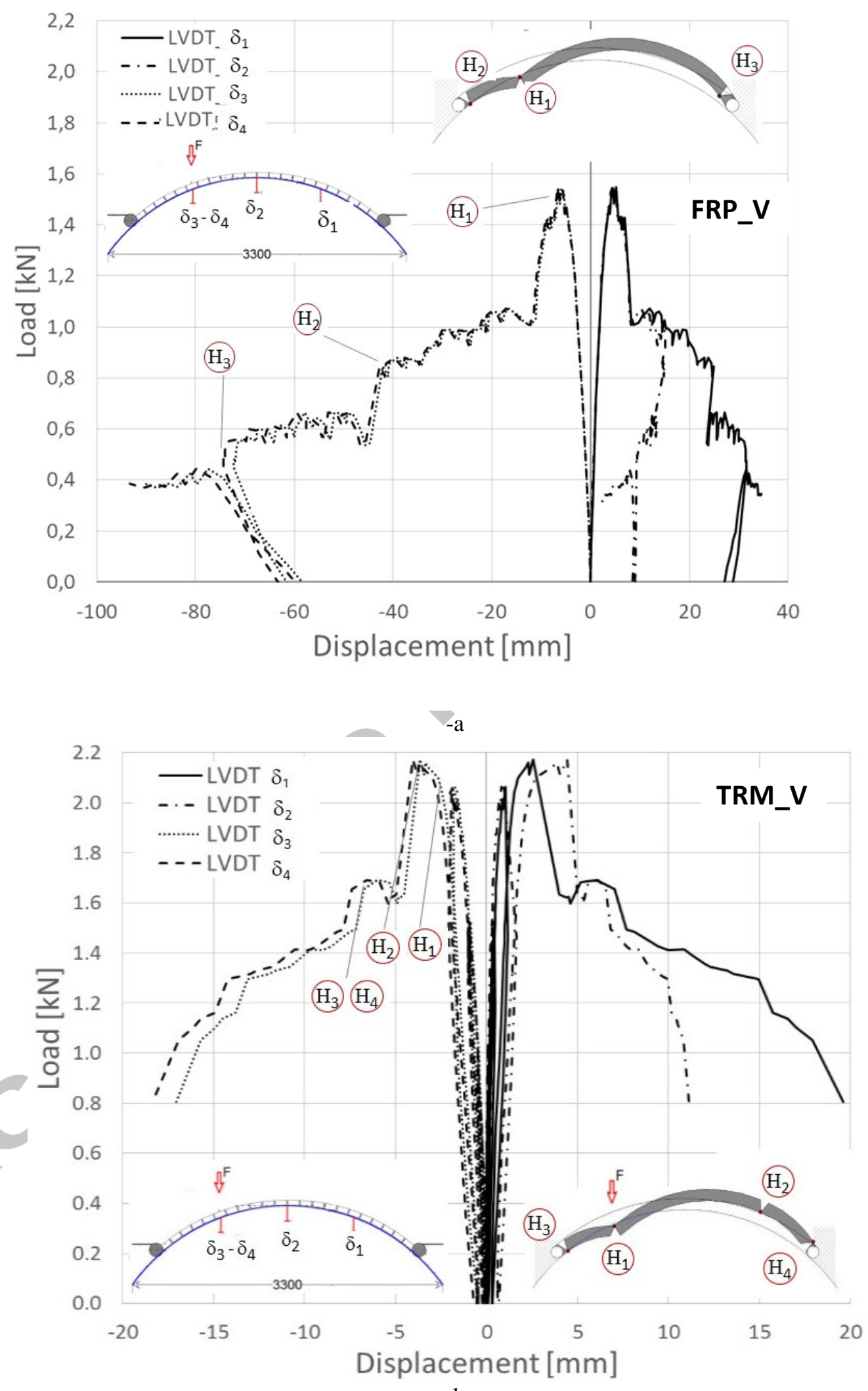

$-b$

Figure 16 - Load-displacement behavior: a- FRP_V, b- TRM_V 


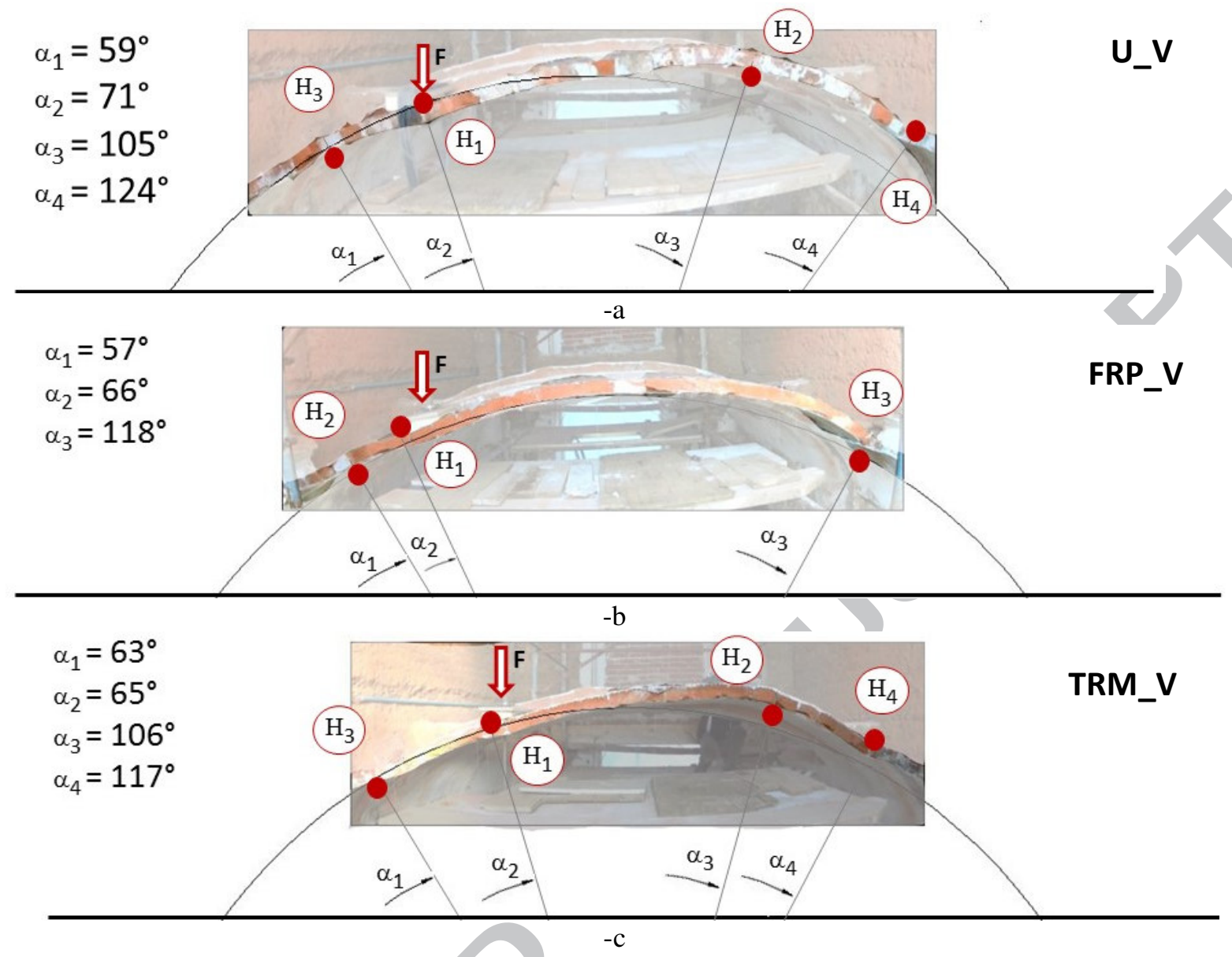

Figure 17: Order of the hinges opening, -a: unreinforced vault; b- FRP reinforced vault (FRP_V); c-TRM reinforced vault (TRM_V) 

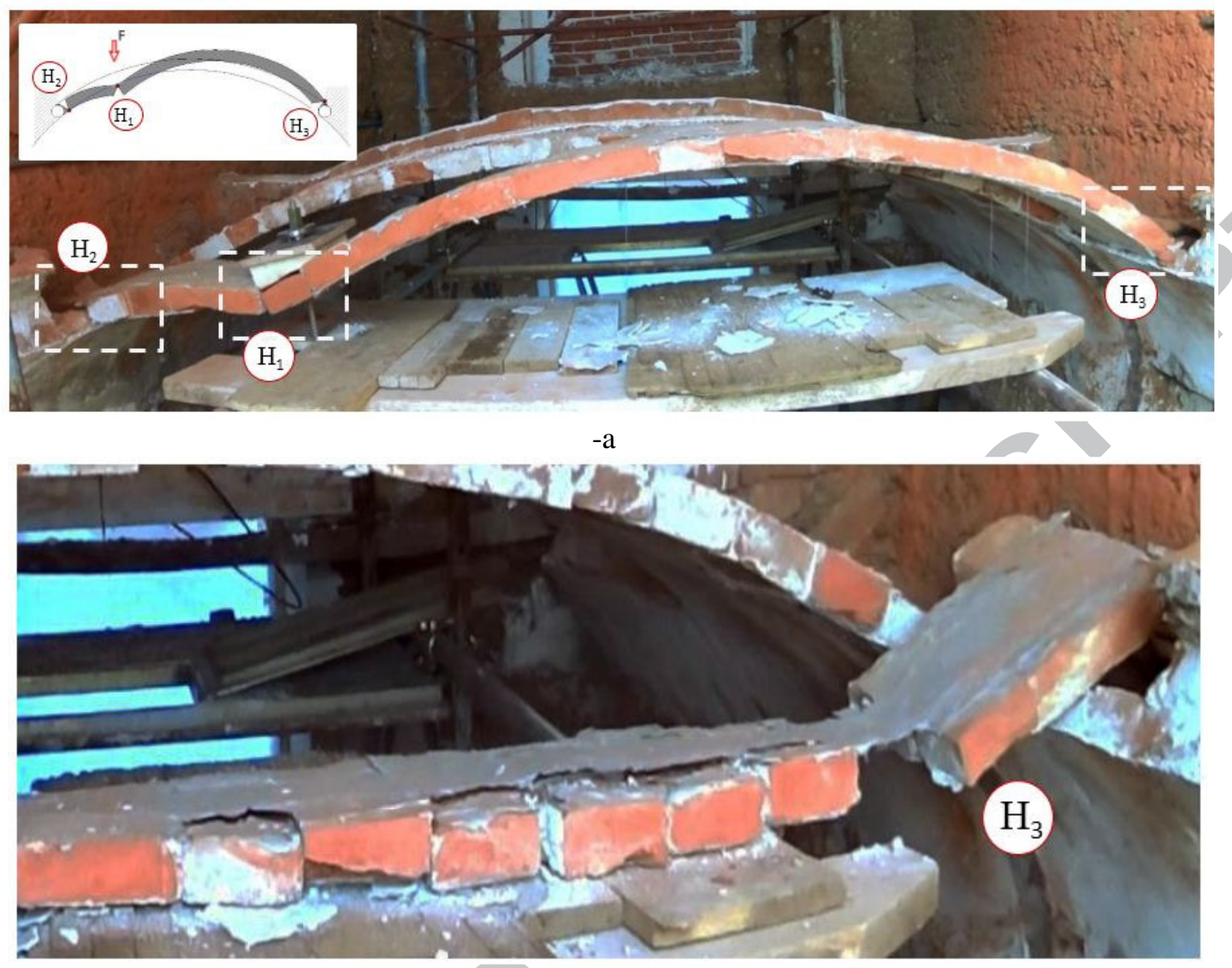

$-b$

Figure 18: Failure mode for FRP_V_a: Appearance of the first and second hinges. -b: FRP debonding.

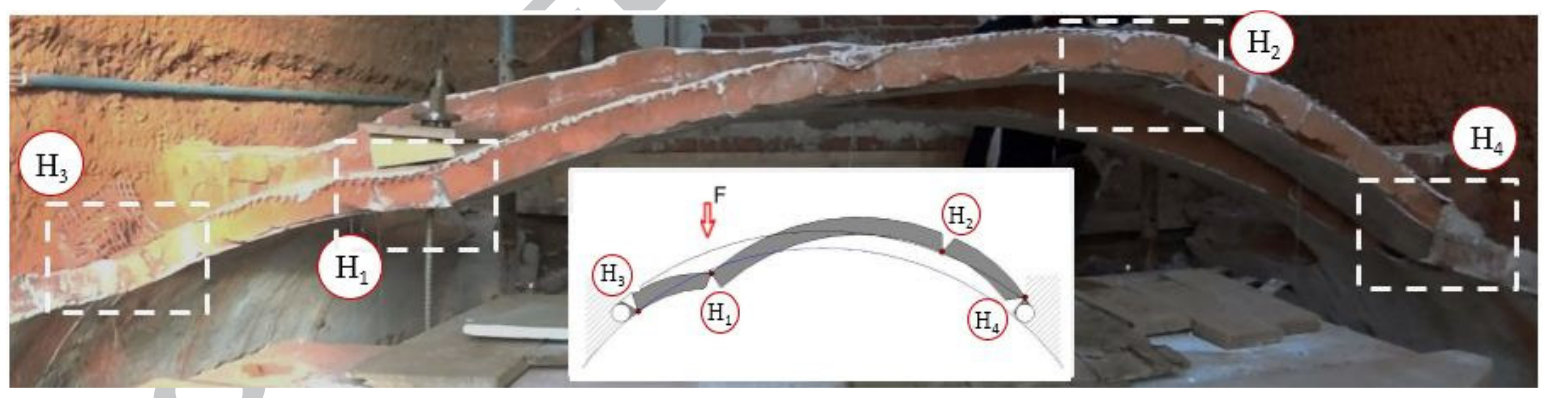

$-\mathrm{a}$

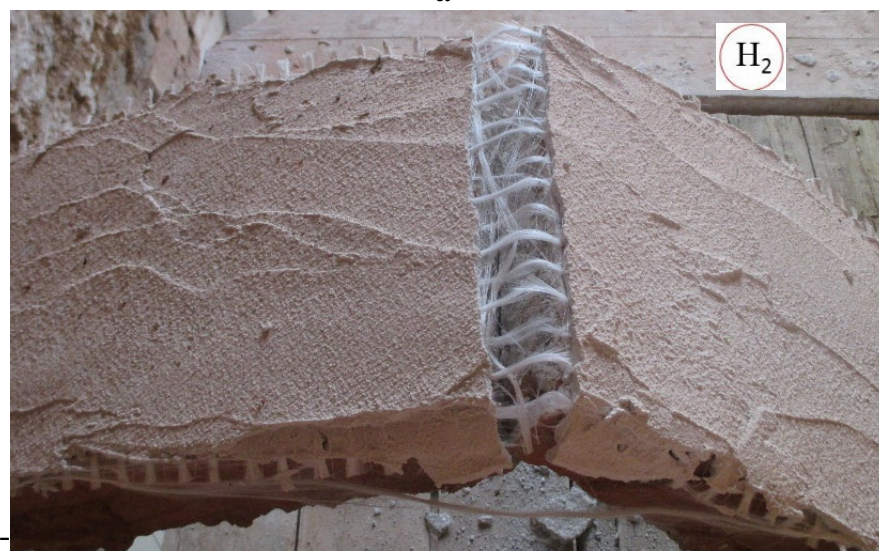

$-b$

Figure 19: Failure mode of TRM_V. -a: hinges appearance. -b: TRM collapse. 


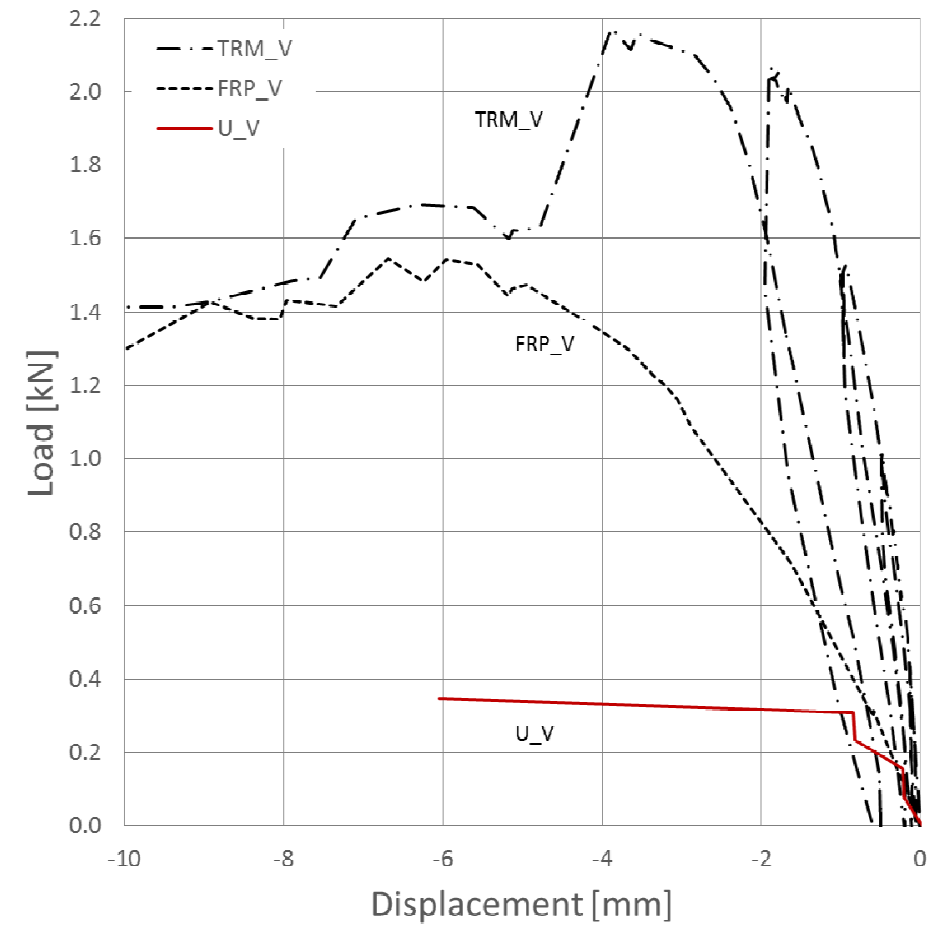

$-\mathrm{a}$
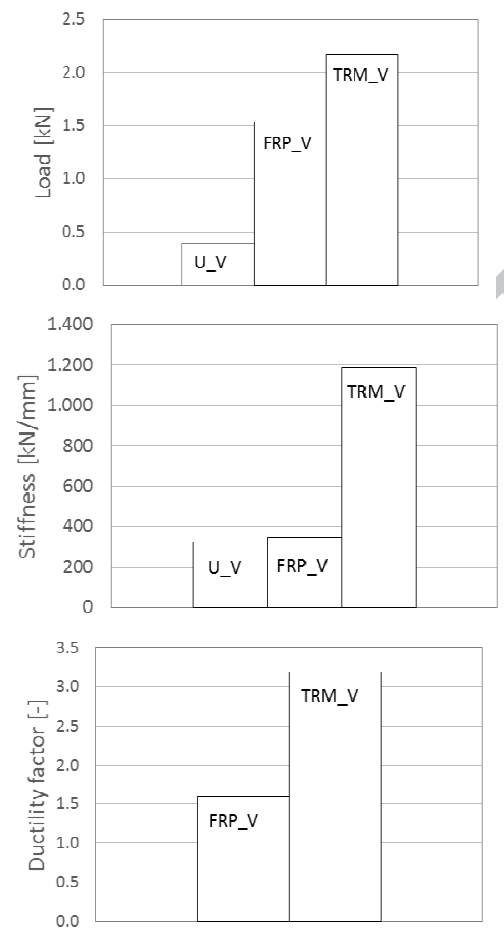

$-\mathrm{b}$

Figure 20: Comparison between unreinforced (U_V) and reinforced (FRP_V and TRCM_V) vaults. -a: Load-displacement curves. -b: Load, stiffness and ductility comparison.

In Figure 20 a concise comparison among the experimental results obtained for the unreinforced and reinforced barrel vaults (i.e. U_V, FRP_V, TRM_V) is reported. The peak load reached was increased by 4 times using FRP reinforcements and by 5.5 times reinforcing with TRM. The TRM system presents a better behavior also in terms of ductility, that was equal to 1.6 for FRP_V and 3.2 for TRM_V. On the opposite, the application of the TRM resulted into a relevant increment in the stiffness of the structure.

\section{Conclusions}

The present project analyzed the performance of ancient masonry arches and vault strengthened with composite systems. The work involves the experimental evaluation and the development of numerical and analytical simulations. In this paper (the numerical validation is discussed in [1]) the experimental campaign was described.

The in situ experimentation was performed on a ribbed barrel vault belonging to an ancient masonry building located in the north-west of Italy. Prior to experimentation, the ribbed barrel vault was transversally cut in order to isolate the arch and to have three vault elements. One arch and one vault remained unreinforced, instead the second arch was reinforced with a SRG system applied at the extrados, the second and third vaults were strengthened with FRP and TRM composite materials.

The mechanical properties of the masonry were determined with a compression test on a masonry element extracted from the arch after the collapse. Moreover the compressive and tensile strength and the elastic modulus of the bricks were experimentally evaluated. 
A complete experimental characterization of the three reinforcement systems was performed. First of all the mechanical properties of the components materials were investigated. After that the tensile and bond properties of the systems were analyzed. The results of this characterization are useful to calibrate the mechanical properties involved in the simulations described in the second part of the project.

The reinforcement systems were very efficient. In particular, the maximum load reached on the unreinforced arch was increased by 4 times by the contribution of SRG system, even if the application of the SRG caused a relevant increment in the stiffness of the structure. In the decreasing phase the reinforced structure was able to keep a high load -fairly constant- for larger displacement values, which demonstrates the satisfactory ductility of the system.

Also the maximum load reached in the tests on the vaults increased significantly. The peak load reached was increased by 4 times reinforcing with FRP and by 5.5 times reinforcing with TRM. The TRM system presents a better behavior also in terms of ductility, that was equal to 1.6 for FRP_V and 3.2 for TRM_V. On the opposite, the application of the TRM resulted into a relevant increment in the stiffness of the structure. The FRP systems modified the typical failure mode, because FRP prevented the appearance of the second hinge at the extrados at the third quarter of the span. The second hinge appeared at the left abutment and the collapse was caused by the detachment from the right abutment.

In the second part of the project [1], described in detail in an accompanying paper, such experimental results will be compared with a straightforward but advanced lower bound limit analysis code, ex-novo implemented just for the present experimental interpretation. Such approach, within the hypotheses of classic limit analysis, allows to account for both the limited masonry compressive strength and shear sliding. In particular, it will be addressed how the hypothesis of notension material (thrust lines) is physically adequate in the unreinforced case, but provides rather conservative results, whereas in presence of reinforcement the assumption of a four hinges mechanism for the collapse can be quite debatable, leading to an unsafe prediction of the ultimate load carrying capacity.

\section{Acknowledgements}

T.C.S. S.r.l. took of care the in situ application of the reinforcement systems and prepared the samples.

The materials characterization was performed at the Testing Laboratory for Materials, Structures and Constructions of Politecnico di Milano. Their financial support is gratefully acknowledged.

Part of the analyses were developed within the activities of Rete dei Laboratori Universitari di Ingegneria Sismica - ReLUIS for the research program funded by the Dipartimento di Protezione Civile.

\section{References}

[1] Bertolesi E., Milani G., Carozzi F.G., Poggi C. (2017). Ancient masonry arches and vaults strengthened with TRM and FRP composites: Numerical analyses. Composite Structures. Under review.

[2] Nanni A. (2012). A new tool for concrete and masonry repail. Concrete international, April 2012: 43-49

[3] Valluzzi M.R., Valdemarca M., Modena C. (2001). Behavior of brick masonry vaults strengthened by FRP laminates. Journal of Composites for Construction, 5(3): 65-71

[4] Foraboschi P. (2004). Strengthening of masonry arches with fiber-reinforced polymer strips. Journal of Composites for Construction, 8(3) : 191-202 
[5] Borri A., Castori G., Corradi M. (2011) Intrados strengthening of brick masonry arches with composite materials. Composites : Part B, 42 : 1164-1172

[6] Corradi M., Borri A., Castori G., Coventry K. (2105). Experimental analysis of dynamic effects of FRP reinforced masonry vaults. Materials, $8: 8059-8071$

[7] Carozzi F.G., Colombi P., Fava G., Poggi C. (2016). Mechanical and bond properties of FRP anchor spikes in concrete and masonry blocks. Composite Structures. In print

[8] Oliveira D.V., Basilio I., Lourenco P.B. (2010). Experimental behavior of FRP strengthened masonry arches. Journal of Composites for Construction, 14 (3) : 312-322

[9] Valluzzi M.R., da Porto F., Garbin E., Panizza M. (2014). Out-of-plane behaviour of infill masonry panels strengthened with composite materials. Materials and Structures, 47 (12) : 2131-2145

[10] D’Ambrisi A., Mezzi M., Feo L., Berardi V.P. (2014). Analysis od masonry structues strengthened with polymeric net reinforced cementitious matrix materials. Composite Structures, 113 (1); 264-271

[11] Ramaglia G. Lignola G.P., Balsamo A., Prota A., Manfredi G. (2017). Seismic strengthening of masonry vaults with abutments using textile-reinforced mortar. Journal of Composites for Construction, 21 (2)

[12] Sarhosis V., De Santis S., de Felice G. (2016). A review of experimental investigation adn assessment methods for masonry arch bridges. Structure and infrastructure engineerin, 12 (11): 1439-1464

[13] Borri A., Casadei P., Castori G., Hammond J., (2009). Strengthening of brick masonry arches with externally bonded steel reinforced composites. Journal of Composites for Construction, $13(6): 468-475$

[14] Alecci V., Misseri G., Rovero L., Stipo G., De Stefano M., Feo L., Luciano R. (2016). Experimental investigation on masonry arches strengthened with PBO-FRCM composite. Composites Part B, $100: 228-239$

[15] De Santis S., Roscini F. de Felice G. (2017). Retrofitting masonry vaults with basalt textile reinforced mortar. Key Engineering Materials, 747 : 250-257

[16] Incerti A., Santandrea M., Carloni C., Mazzotti C. (2017). Desctructive in-situ tests on masonry arches strengthened with FRCM composite materials. Key Engineering Materials, $747: 567-573$

[17] Gattesco N., Boem I., Gubana A., Menegon D., Bello N., Dudine A. (2017). Experimental behavior of masonry vaults strengthened with thin extradoxal or intradoxal layer of fiber reinforced lime mortar. Key Engineering Materials, 747 : 275-281

[18] EN14580. Natural stone test methods - Determination of static elastic modulus; 2005

[19] EN 12390-6. Testing hardened concrete - Part 6: Tensile splitting strength of test specimens; 2009

[20] EN 772-1. Methods of test for masonry units - Part 1 : Determination of compressive strength ; 2011

[21] EN ISO 10618/2005. Carbon fibre - determination of tensile properties of resin-impregnated yarn; 2005.

[22] ISO 15630-3. Steel for the reinforcement and prestressing of concrete - Test methods ; 2010

[23] Ascione L., de Felice G., De Santis D. (2015). A qualification method for externally bonded Fibre Reinforced Cementitious Matrix (FRCM) strengthening systems. Composites Part B, $78: 1-10$

[24] De Santis S., Ceroni F., de Felice G., Fagone M., Ghiassi B., Kwiecień A., Lignola G.P., Morganti M., Valluzzi M.R.,Viskovic A. (2017). Round Robin Test on tensile and bond behaviour of Steel reinforced Grout systems. Composites Part B, 127: 121-132

[25] Lignola G.P., Caggegi C., Ceroni F., De Santis S., Krajewski P., Lourenco P.B. Morganti M., Papanicolaou C., Pellegrino C., Prota A., Zuccarino L. (2017). Performance assessment of basalt FRCM for retrofit applications on masonry. Composites Part B, $128: 1-18$ 
[26] Carozzi F.G., Bellini A., D’Antino T., de Felice G., Focacci F., Hojdys L., Laghi L., Lanoye E., Micelli F., Panizza M., Poggi C. (2017). Experimental investigation of tensile and bond properties of Carbon-FRCM composites for strengthening masonry elements. Composites Part B, $128: 100-119$

[27] Caggegi C., Carozzi F.G., De Santis S., Fabbrocino F., Focacci F., Hojdts L., Lanoye E., Zuccarino L. (2017). Experimental analysis on tensile and bond properties of PBO and aramid fabric reinforced cementitious matrix for strengthening masonry structures. Composites Part B, $127: 175-195$

[28] Leone M., Aiello M.A., Balsamo A., Carozzi F.G., Ceroni F., Corradi M., Gams M., Garbin E., Gattesco N., Krajewski P., Mazzotti C., Oliveira D., Papanicolaou C., Ranocchiai G., Roscini F., Saenger D. (2017). Glass fabric reinforced cementitious matrix: tensile properties and bond performance on masonry substrate. Composites Part B, in print

[29] Butler M, Mechtecherine V, Hemplel S. Durability of textile reinforced concrete made with AR glass fibre: effect of matrix composition. Mater Struct. 2010;43:1351-68.

[30] Carozzi F.G., Poggi C. (2015). Mechanical properties and debonding strength of Fabric Reinforced Cementitious Matrix (FRCM) systems for masonry strengthening. Composites: Part B, 70: 215-230

[31] De Santis S., de Felice G. (2015). Steel reinforced grout systems for the strengthening of masonry structures. Composite Structures, 134: 533-548

[32] De Santis S., Carozzi F.G., de Felice G., Poggi C. (2017). Test methods for Textile Reinforced Mortar systems. Composites Part B, 127: 121-132

[33] ASTM C1583/C1583M - 13 Tensile Strength of Concrete Surfaces and the Bond Strength or Tensile Strength of Concrete Repair and Overlay Materials by Direct Tension (Pull-off Method); 2014

[34] Bianchi G., Carozzi F.G., Poggi C., Nanni A. (2014). Fabric-reinforced-cementitious-matrix (FRCM) per la riabilitazione strutturale: aderenza al supporto. International conference Rehabend. 2014

[35] Razavizadeh A., Ghiassi B., Oliveira D.V., (2014). Bond behavior of SRG-strengthened masonry units: testing and numerical modeling. Construction and building materials, 64: 387397

[36] De Santis S., de Felice G. (2015). Steel reinforced grout systems for the strengthening of masonry structures. Composite Structures, 134: 533-548

[37] UNI EN 2561. Aerospace Series - Carbon Fibre Reinforced Plastics - Unidirectional Laminates - Tensile Test Parallel To The Fibre Direction. Italian Standards

[38] Valluzzi M.R. et al., (2012). Round Robin Test for composite-to-brick shear bond characterization. Materials and Structures, 45 (12): 1761-1791

[39] Carozzi F.G., Colombi P., Poggi C. (2015). Calibration of end-debonding strength model for FRP-reinforced masonry. Composite Structures, 120: 366-377

[40] De Santis S., de Felice G., Napoli A., Realfonzo R. (2016) Strengthening of structures with Steel Reinforced Polymers: A state-of-the-art review. Composites Part B, 104: 87-110

[41] Ceroni F. (2017). Bond tests to evaluate the effectiveness of anchoring devices for CFRP sheets epoxy bonded over masonry elements. Composites Part B, 113: 317-330

[42] CNR DT200/2012. Guide for the design and construction of externally bonded FRP systems for strengthening existing structures. National Research Council. 2012 